\title{
Kiguchi Method, A Novel Simplified Technique For Pancreaticojejunostomy In Minimally Invasive Pancreaticoduodenectomy, Significantly Reduces Postoperative Pancreatic Fistula Rate In Patients With A Soft Pancreatic Texture
}

Gozo Kiguchi ( $\sim$ gozo_kiguchi@me.com )

Fujita Health University https://orcid.org/0000-0003-2185-3275

Atsushi Sugioka

Fujita Health University

Masaya Nakauchi

Fujita Health University

Masayuki Kojima

Fujita Health University

Akira Yasuda

Fujita Health University

Sanae Nakajima

Fujita Health University

Yoshinao Tanahashi

Fujita Health University

Koichi Suda

Fujita Health University

Yutaro Kato

Fujita Health University

Ichiro Uyama

Fujita Health University

Research article

Keywords: laparoscopic surgery, robotic surgery, pancreaticoduodenectomy, pancreaticojejunostomy, pancreatic fistula

Posted Date: September 28th, 2020

DOI: https://doi.org/10.21203/rs.3.rs-76988/v1 
License: (c) (i) This work is licensed under a Creative Commons Attribution 4.0 International License. Read Full License 


\section{Abstract}

Background: Minimally invasive pancreaticoduodenectomy (MIPD), including laparoscopic pancreaticoduodenectomy (LPD) and robotic pancreaticoduodenectomy (RPD), is especially demanding due to pancreaticojejunostomy (PJ). Postoperative pancreatic fistula (POPF) remains the most serious complication in MIPD as well as in open pancreaticoduodenectomy (OPD). Conventional PJ in MIPD did not improve the POPF rate and hospital stay, contrary to expectations. High POPF rates have been attributed to technical issues encountered during MIPD, including motion restriction and insufficient water tightness; therefore, we have developed the Kiguchi method as a novel PJ technique optimized for MIPD. Herein, we describe the technique and assess its impact in patients with a soft pancreatic texture, which has been reported to be significantly related to POPF.

Methods: The retrospective study included 188 patients with a soft pancreatic texture. Briefly, 143 patients underwent OPD with conventional PJ (OPD group); 19 patients underwent MIPD with conventional PJ (Old-MIPD group), including 7 and 12 patients undergoing LPD and RPD, respectively; and 26 patients underwent MIPD using the Kiguchi method (New-MIPD group), including 15 and 11 patients undergoing LPD and RPD, respectively. Short-term outcomes were assessed, and POPF risk factors were determined using univariate and multivariate analyses.

Results: The grade B/C POPF rate was significantly lower in the New-MIPD group than in the Old-MIPD and OPD groups (3.8\% vs. $42.1 \%$ and $36.4 \%$, respectively). The median hospital stay was significantly shorter in the New-MIPD group than in the Old-MIPD and OPD groups (23 vs. 33 and 31 days, respectively). By multivariate analysis, the PJ method and male sex were significant POPF risk factors. Among the patients without POPF, the hospital stay was significantly shorter in those undergoing MIPD than in those undergoing OPD, suggesting the advantage of MIPD.

Conclusions: The novel Kiguchi method significantly reduced the POPF rate in patients with a soft pancreatic texture.

\section{Introduction}

Among gastrointestinal surgeries, pancreaticoduodenectomy (PD) is not only a technically demanding resection method but also features complicated reconstruction. Failure of pancreaticojejunostomy (PJ) can result in postoperative pancreatic fistula (POPF), which occasionally causes severe infections and postoperative intra-abdominal hemorrhage as early fatal complications after PD [1-4]. The most important factor associated with POPF development is a soft pancreatic texture, which tends to accompany benign and low-grade malignant tumors of the pancreatic head and lower bile duct cancer [5-8].

In recent years, minimally invasive surgery has become widespread especially in gastrointestinal surgery due to its ability to reduce intraoperative blood loss, postoperative hospital stay, and postoperative shortterm complications compared to open surgery [9-11]. Minimally invasive PD (MIPD) has been also 
gradually spreading based on similar advantages it is expected to provide [12]. Furthermore, coverage of laparoscopic PD (LPD) for benign and low-grade malignant tumors by the national insurance in Japan starting in April 2016 has facilitated its widespread use. However, it remains unclear whether MIPD improves postoperative short-term outcomes compared to open PD (OPD) [13]. One of the comparative clinical trials comparing LPD with OPD was discontinued due to the high mortality rate of LPD [14]. This failure was later attributed to the extreme difficulty in performing intracorporeal PJ during MIPD [15], and some surgeons prefer extracorporeal PJ through a small laparotomy. However, extracorporeal PJ is a demanding procedure, and the POPF rate remains high in the absence of advantages of minimally invasive surgery. To the best of our knowledge, no randomized controlled trials investigated optimal PJ methods for MIPD. In our institution, with the expectation of harnessing the advantages of minimally invasive surgery, LPD and robotic PD (RPD) were introduced in 2008 and 2009, respectively, for intracorporeal conventional PJ. However, the observed high POPF rate and the consequent prolonged postoperative hospital stay were contrary to our expectations. Therefore, based on the hypothesis that the POPF rate should be improved by minimizing technical errors during PJ, the Kiguchi method was developed to accomplish PJ in MIPD.

We herein provide a detailed description of the novel Kiguchi method for PJ in MIPD and elucidate the significance of this method by comparing outcomes of the novel Kiguchi method and those achieved with conventional MIPD and OPD. Patients enrolled in the present study were confined to those with a soft pancreatic texture because of its reported significant association with POPF rates of as high as $20 \%$ not only after OPD but also after MIPD $[16,17]$.

\section{Materials And Methods}

\section{Patient selection}

This retrospective review of prospectively collected data included the review of all 336 patients who underwent PD for periampullary lesions between January 1, 2008 and March 31, 2020 in the study institution. The institutional review board approved the study protocol (approval number: HM19-064).

The present study included 188 patients with a soft pancreatic texture among the 336 patients. First, the degree of pancreatic fibrosis in pancreatic remnant was subjectively classified as soft or hard by experienced pancreatic surgeons during surgery and 146 patients with a hard pancreatic texture, including 35 patients who required concomitant resection and reconstruction of the vasculature and/or other organs, were excluded. Two patients who underwent PJ via a small upper middle incision by conversion from MIPD were also excluded from the study cohort. The remaining 188 patients who were included in the final analyses were classified as follows: OPD group, 143 patients who underwent OPD with conventional PJ between January 2008 and March 2020; Old-MIPD group, 19 patients who underwent MIPD with conventional PJ, including seven patients who underwent LPD between 2008 and 2016 and 12 patients who underwent RPD between 2009 and 2016; New-MIPD group, 26 patients who underwent MIPD with the Kiguchi method between September 2016 and March 2020, including 15 
patients who underwent LPD and 11 patients who underwent RPD. In the RPD group, the da Vinci Si or Xi platform (Intuitive Surgical, Mountain View, CA, USA) was used. The patients enrolled in the study are summarized in Fig. 1.

\section{Development of the Kiguchi method}

Based on our experience, the high POPF rate in MIPD using conventional PJ is attributed to several technical errors even with robotic surgery. Briefly, these potential technical errors are primarily a result of the motion restriction of forceps, insufficient water tightness of the PJ, and entanglement and confusion of the many threads. The Kiguchi method is a simple and feasible PJ technique to resolve these technical errors which are intricately intertwined with each other.

\section{Details of the Kiguchi method}

\section{Patient position and placement of trocars}

The patient is placed in a reverse Trendelenburg position. In LPD, five trocars, including three 12-mm and two 5-mm trocars, are used for resection and two 3-mm trocars are added for PJ (Fig. 2). In RPD, five trocars, including one 12-mm and four 8-mm trocars, are used for resection and one 12-mm trocar is added for PJ (Fig. 3).

\section{Pancreatic transection}

The pancreas is transected using an auto-suturing device. The stump of main pancreatic duct is identified in the staple line of remnant pancreas. Using scissors, staples only around the main pancreatic duct are removed and the main pancreatic duct is opened. The pancreatic duct tube as large as possible is inserted as a temporary test tube.

\section{Extracorporeal maneuver: seromuscular excision of the jejunal loop}

The jejunal loop is pulled out from a small incision in the umbilicus, and the seromuscular layer at the PJ site is excised. The seromuscular layer of the jejunal loop is repeatedly excised longitudinally (Fig. 4A), and the range is expanded until a sufficient width is obtained to cover the pancreatic stump. A pancreatic duct tube with a nodule is inserted through the middle of seromuscular excision into the jejunal lumen and is reeled out from the site of choledochojejunostomy. The jejunal wall orifice that is as small as possible is created using the metal tip of the tube; it is important to select the largest tube that can be inserted into the main pancreatic duct. Finally, two 12-cm 5-0 polydioxanone sutures with double needles are tied and fixed around the tube (Fig. 4B).

\section{Intracorporeal maneuver}

Reconstruction is performed using PD-II. The jejunal loop is pulled up to the pancreatic stump via a retrocolic course. PJ is performed at approximately $15 \mathrm{~cm}$ from the jejunal loop stump. First, a 12-mm

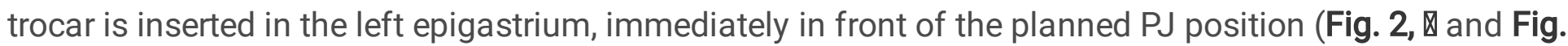


3, 口). For outer-layer sutures, three transpancreatic stitches in a horizontal mattress fashion are placed: Two transpancreatic sutures are placed on both sides as apart from the main pancreatic duct, and the remaining sutures are placed interposing the main pancreatic duct.

First, a double-needle stitch is passed through the jejunal loop from $1 \mathrm{~cm}$ behind the seromuscular excision to the posterior edge, which is then crossed over the pancreas at least $1 \mathrm{~cm}$ from the stump. Thereafter, transpancreatic stitches are exteriorized through the 12-mm trocar to prevent entanglement (Fig. 4C). The inner-layer suture is also placed in a horizontal mattress fashion with double-ended needles from inside to outside of the main pancreatic duct lumen. The detailed operative procedure using the Kiguchi method is described in Fig. 5. Custom-made 12-cm-long 5-0 non-absorbable monofilament threads with double-ended needles are used to reduce the risk of entanglement in abdominal cavity. Two horizontal mattress sutures, which are placed on ventral (Fig. 6, प) and dorsal sides (Fig. 6, प) of the main pancreatic duct, are then held with microvascular clips. Cranial (Fig. 6, 0 ) and caudal (Fig. 6, [) sides of the main pancreatic duct are stitched with a single interrupted suture to the pancreatic stump without passing through the lumen. Using one end of each of the four suture needles placed on the pancreatic stump, the jejunal wall around the orifice is stitched one by one and ligated in order, as shown in Fig. 6 . Contrary to the conventional duct-to-mucosa anastomosis, in which 6-8 interrupted stitches are placed in a radial direction around the main pancreatic duct, the Kiguchi method utilizes only two horizontal mattress sutures and two interrupted sutures, which are placed to surround the main pancreatic duct in a square pattern and to obtain tight adhesion to the jejunal submucosal layer around the main pancreatic duct using a minimum number of threads. After ligating the thread on the dorsal side (Fig. 6, $\square-\square$ ), the tip of the pancreatic duct tube is inserted into the main pancreatic duct (Fig. 4D). The position of the pancreatic duct tube is adjusted and fixed to the anterior wall of the pancreatic duct and the jejunal orifice using the prepared suture threads. During the ligation of inner-layer suture, the pancreatic stump and jejunal loop are approximated by pulling the outer-layer suture threads from outside of the abdominal cavity (Fig. 4E). In the final stage of PJ using the Kiguchi method, ventral edge of the seromuscular layer of the jejunal loop is sutured using horizontal mattress stitches (Fig. 4F). Meanwhile, the pancreatic duct tube is cut off and dropped into the jejunal lumen as a long lost stent.

\section{Selection of operative procedures}

In the present study, all patients were evaluated for indications for up-front surgery. The surgery type, OPD or MIPD, was determined based on patient preference, because MIPD was not covered by the national insurance until May 2016. Since June 2016, LPD for benign or low-grade malignant tumors has been covered by the national insurance and patients meeting the criteria tended to choose LPD. RPD was not covered by the national insurance until March 2020, and selection of RPD primarily depended on the patient's economic conditions. Between January 2008 and August 2016, 19 patients in the Old-MIPD group underwent MIPD with conventional PJ by a single surgeon (IU). Between September 2016 and March 2020, 26 patients in the New-MIPD group underwent MIPD with PJ using the Kiguchi method by two surgeons (IU, GK). Between January 2008 and March 2020, 143 patients in the OPD group underwent 
OPD with conventional PJ by several pancreatic surgeons with experience of more than 30 conventional PJ cases with OPD, including two surgeons involved in MIPD.

\section{Operative procedures}

\section{Resection}

All patients underwent subtotal stomach-preserving PD. In the New-MIPD group, the novel semi-derotation technique developed by our group was applied for resection, as described in detail elsewhere [18].

\section{Reconstruction}

In all patients, modified Child's method was used for reconstruction. The end-to-side PJ was performed at approximately $15 \mathrm{~cm}$ distal to the jejunal loop stump in a retrocolic fashion.

\section{PJ}

\section{OPD group: conventional PJ}

Operative procedures in the OPD group were performed through either a midline laparotomy or bilateral subcostal incision. Pancreas was dissected with a scalpel to identify the main pancreatic duct. Interrupted duct-to-mucosa anastomosis was used for PJ in an end-to-side fashion. Cut surface of the remnant pancreas was approximated to the jejunal serosal layer, with three or four interrupted penetrating sutures using the modified Kakita method (Fig. 7) or interrupted horizontal mattress sutures using the modified Blumgart method (Fig. 8) as outer-layer sutures [19, 20]. A duct-to-mucosa anastomosis was formed between the main pancreatic duct and jejunal orifice by interrupted sutures placed in a radial direction using at least six stitches as inner-layer sutures. An external or internal pancreatic duct tube was placed based on the surgeon's preference.

\section{Old-MIPD group: conventional PJ}

Patients were placed in a reverse Trendelenburg position. Five trocars, including three 12-mm and two 5$\mathrm{mm}$ trocars, were used in LPD, whereas five trocars, including two 12-mm and three 8-mm trocars, were used in RPD. Pancreas was dissected with an ultrasonic scalpel to identify the main pancreatic duct orifice. In the Old-MIPD group, all patients underwent conventional intracorporeal PJ similar to that performed in the OPD group. In RPD, inner-layer sutures for duct-to-mucosa anastomosis were performed using at least six single interrupted sutures placed in a radial direction. In contrast, only four single interrupted sutures were performed in LPD because of technical difficulty. An external pancreatic duct tube was placed in all patients.

\section{New-MIPD group: the Kiguchi method}

Intracorporeal PJ using the Kiguchi method described above was performed in all patients in the NewMIPD group who underwent surgery via LPD or RPD. 


\section{Choledochojejunostomy}

In all groups, end-to-side choledochojejunostomy was performed using continuous sutures for the posterior layer and interrupted sutures for the anterior layer.

\section{Drainage tube management}

In all groups, two or three soft silicone drains were indwelled around the PJ.

Patients were treated in the intensive care unit for at least one day before their transfer to the general ward. For POPF diagnosis based on the International Study Group on Pancreatic Surgery (ISGPS) definition, amylase concentration via the drainage tube was measured daily for a minimum of three days after surgery. The drainage tube was removed on postoperative day 3-7 in the absence of drain effusion as evidence for POPF. In patients with POPF, the drainage tube was exchanged at the appropriate timing until the drainage fluid became negligible.

\section{Study outcomes}

The following clinical characteristics were analyzed: use of robotic surgery, age, sex, body mass index, American Society of Anesthesiologists physical status score, main pancreatic duct diameter, presence of malignancy, use of biliary drainage, and presence of diabetes mellitus as a comorbidity. A main pancreatic duct with a diameter of $<3 \mathrm{~mm}$ was defined as narrow. The operative and postoperative data in the present study included PJ length, postoperative complications, duration of drain indwelling, and postoperative hospital stay.

Postoperative complications were defined according to the Clavien-Dindo classification [21]. POPF, one of the most important postoperative complications of PD, was classified in accordance with the 2016 ISGPS guidelines [22]. Postoperative surgery-related complications were determined according to the ISGPS definitions $[23,24]$. Postoperative mortality was defined as death occurring within 90 postoperative days. Grade B/C POPF was defined as the primary endpoint for univariate and multivariate risk factor analyses.

\section{Statistical analysis}

Continuous variables were presented as medians with range (minimum to maximum), and categorical variables are reported as numbers and percentages. The New-MIPD group was compared with the OldMIPD and OPD groups using Pearson's chi-squared test for categorical variables and the Mann-Whitney $U$ test for continuous variables.

A $p$ value of less than 0.05 was considered to indicate statistical significance. All preoperatively parameters significantly correlating with POPF were included in a multivariate binary logistic regression model. All statistical analyses were performed with SPSS version 23.0 for Windows (Statistical Package for the Social Sciences, Chicago, IL). 


\section{Results}

\section{Patient characteristics}

The clinical characteristics of study patients are presented in Tables 1 (New-MIPD vs Old-MIPD) and 2 (New-MIPD vs OPD). The ratio of RPD was not significantly different between the New-MIPD and OldMIPD groups. The proportion of male patients was higher in the OPD group than in the New-MIPD group

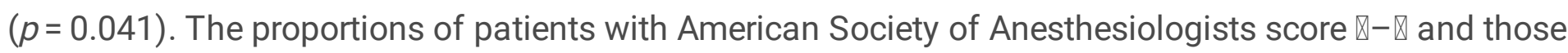
with a main pancreatic duct diameter of $<3 \mathrm{~mm}$ were higher in the Old-MIPD group than in the New-MIPD group ( $p=0.026$ and $p=0.006$, respectively). The proportion of patients with malignancy was lower in the New-MIPD group compared with both the Old-MIPD and OPD groups $(p=0.001$ and $p<0.001$, respectively). The proportion of preoperative biliary drainage use was higher in the OPD group than in the New-MIPD group $(p=0.026)$. There were no significant differences in age, body mass index, and diabetes as comorbidity among the New-MIPD, Old-MIPD, and OPD groups.

\section{Perioperative and postoperative results}

Operative findings and short-term outcomes in three study groups are summarized in Tables 3 (NewMIPD vs Old-MIPD) and 4 (New-MIPD vs OPD). The median PJ duration was significantly longer in the New-MIPD group than in the OPD group (104 vs $40 \mathrm{~min} ; p<0.001$ ). The rate of grade B/C POPF was significantly lower in the New-MIPD group than in both the Old-MIPD and OPD groups (3.8\% vs $42.1 \%$ and $36.4 \%$, respectively; $p=0.002$ and $p<0.001$, respectively). Similarly, the rate of intra-abdominal abscesses was significantly lower in the New-MIPD group than in both the Old-MIPD and OPD groups ( $3.8 \%$ vs $31.5 \%$ and $21.0 \%$, respectively; $p=0.017$ and $p=0.026$, respectively). The rates of other postoperative complications, such as bile leakage, delayed gastric emptying, gastrointestinal bleeding, and postpancreatectomy hemorrhage, were not significantly different among the three groups. The overall rate of postoperative Clavien-Dindo grade $\nabla-\varangle$ complications was significantly lower in the New-MIPD group than in both the Old-MIPD and OPD groups (23.1\% vs $52.6 \%$ and $47.6 \%$, respectively; $p=0.041$ and $p=0.021$, respectively). Additionally, the median duration of drain indwelling was significantly shorter in the NewMIPD group than in both the Old-MIPD and OPD groups (5.5 vs 14 and 10 days, respectively; $p=0.002$ and $p<0.001$, respectively). Furthermore, the median duration of postoperative hospital stay was significantly shorter in the New-MIPD group than in both the Old-MIPD and OPD groups (23 vs 33 and 31 days, respectively; $p=0.007$ and $p<0.001$, respectively).

The duration of hospital stay for all patients in the New-MIPD, Old-MIPD, and OPD groups are presented in Fig. 9 and Fig. 10. The rate of postoperative hospital stay for more than one month was significantly lower in the New-MIPD group than in both the Old-MIPD and OPD groups (3.8\% vs $52.6 \%$ and $43.4 \%$, respectively; $p<0.001$ and $p<0.001$, respectively). Eight and thirty-nine patients in the Old-MIPD and OPD groups, respectively, were hospitalized for more than one month due to extended POPF treatment. In contrast, only one patient in the New-MIPD group required hospitalization for more than one month due for treatment of bile leakage caused by obstruction of the jejunal loop. There was no statistically significant difference in mortality rate among the three groups. While there was no mortality in the New- 
MIPD group, 1 (5.23\%) and 2 (1.4\%) patients in the Old-MIPD and OPD groups, respectively, died. Comparison of the duration of hospital stay among patients without POPF revealed no significant difference in the median duration of postoperative hospital stay between the New-MIPD and Old-MIPD groups (22 and 25 days, respectively; $p=0.55$ ). In contrast, the median duration of postoperative hospital stay among patients without POPF was significantly shorter in the New-MIPD group than in the OPD group (22 vs 26 days, $p=0.049$ ). In addition, among patients without POPF, the median duration of postoperative hospital stay was significantly shorter in the overall-MIPD group than in the OPD group (23 vs 26 days, $p=0.034$ ) (Fig. 11).

\section{Risk factors for POPF}

All preoperative parameters that significantly correlated with POPF rate were included in a multivariate binary logistic regression model. Other parameters included in the multivariate binary logistic regression model were preoperative parameters already known as risk factors for POPF. By univariate analysis, PJ method, age, sex, body mass index, and main pancreatic duct diameter $<3 \mathrm{~mm}$ showed statistically significant differences between the patients with and without POPF. All abovementioned parameters were analyzed by multivariate binary logistic regression to determine independent risk factors for POPF. Consequently, independent risk factors for POPF were PJ method (Old-MIPD vs New-MIPD, odds ratio [OR] $12.79,95 \%$ confidence interval [CI] 1.35-121.55, $p=0.027$; OPD vs New-MIPD, OR 10.51, 95\% Cl 1.35$81.55, p=0.024)$, and male sex (OR 2.78, 95\% Cl 1.34-5.77, $p=0.006$ ) (Table 5).

\section{Discussion}

In the present study, the POPF rate was significantly improved in the New-MIPD group using the Kiguchi method in comparison with both the Old-MIPD and OPD groups using conventional PJ. Since all enrolled patients had a soft pancreatic texture, which has been demonstrated to be the most influential risk factor for POPF [3-8, 25-28], our study design was appropriate to elucidate the optimal PJ method to reduce the risk of POPF. Based on our experience, the POPF rate is attributed to many technical errors intricately intertwined with each other related to conventional PJ used in MIPD. These potential technical errors include motion restriction of forceps, which can cause tearing of pancreatic parenchyma and enlargement of the jejunal orifice, entanglement and confusion of the threads preventing accurate stitch placement, and insufficient water tightness between the pancreatic stump and jejunal loop. Therefore, based on the hypothesis that the POPF rate might be improved by minimizing these technical errors, a new PJ approach, the Kiguchi method, was developed for MIPD. The main technical improvements are as follows (Fig. 12).1.

\section{Overcoming motion restriction of forceps and reduction in thread number}

To overcome the motion restriction of forceps, we designed stitches to be placed only in the perpendicular direction to the forceps axis; the stitches are in vertical direction instead of radial direction to the main pancreatic duct. In fact, stitches in the radial direction must be the fateful cause of failure in conventional 
PJ during MIPD. Furthermore, in the Kiguchi method, only four stitches are placed for inner-layer sutures of PJ. For the main pancreatic duct, the two horizontal mattress sutures that are placed pass through the lumen at the 12- and 6-hour directions whereas the other two stitches in the parenchyma near the duct are in the 3- and 9-hour directions, which prevent the tearing of pancreatic parenchyma. The jejunal loop is sutured by four needle stitches placed in a square pattern, thereby avoiding passing through the jejunal orifice, which prevents the enlargement of jejunal orifice (Fig. 6). These technical improvements ensure that PJ is a simple and secure process in MIPD. Although the motion restriction is improved by using a surgical robot, movement of the needle in the parallel direction to the axis is deceptively demanding and the instability of the robot arm aggravates the difficulty. Moreover, due to the rigidity of the forceps, the risk of tearing pancreatic parenchyma is even higher in patients with a soft pancreatic texture. These speculations are compatible with the observed lack of improvement in POPF rate with RPD in the OldMIPD group. Consequently, pancreatic parenchymal injury might be sufficiently avoided in the Kiguchi method.

Other important technical issues are entanglement and confusion of the threads, which hinder accurate stitch placement. To prevent this technical issue with the Kiguchi method, the number of sutures was reduced to the absolute minimum of seven stitches, which did not impede PJ. The four stitches placed for the inner layer, as described above, as well as the three stiches placed for the outer layer use horizontal mattress sutures. In addition, exteriorization of the transpancreatic stitches of the outer layer through the trocar is useful in preventing entanglement and confusion [29].

\section{Reinforcement of water tightness of the anastomosis}

To reinforce water tightness of the anastomosis in the Kiguchi method, the pancreas is first transected using an auto-suturing device which enhances the adhesion by staples. Second, the pancreatic stump is covered effectively by the adjusted seromuscular-excised area of the jejunal loop (Fig. 13). Preventing the tearing of pancreatic parenchyma and the enlargement of jejunal orifice also contribute to enhanced adhesion. Due to the seromuscular excision of the jejunal loop, the pancreatic stump is invaginated into the intestinal wall and close contact and adhesion are achieved; small branches of the pancreatic duct might also be effectively closed with an auto-suturing device. These factors altogether might aid in achieving sufficient water tightness of the PJ. Incorporating the novel Kiguchi method achieves water tightness and the consequent firm adhesion to the PJ. The design of the Kiguchi method is similar to the invagination method, in that the gap between the pancreatic stump and jejunal loop wall becomes as tight as possible. In the Kiguchi method, instead of creating a large entry hole at the wall of the jejunal loop, which is performed in the invagination method, the seromuscular layer to which the pancreatic stump will later connect is excised and an minimum-sized orifice to pass a pancreatic duct tube is created. As a result, a water-tight invagination can be achieved, which minimizes the risk of fluid leakage compared to other invagination methods. In the Kiguchi method, the gaps between stitches are only around the vertices of the square and the gap can be reduced by using the smallest number of stitches possible (Fig. 14). In contrast, single interrupted stitches used in duct-to-mucosa anastomosis during conventional PJ are placed around the main pancreatic duct in a radial direction and there is a gap

Page $11 / 35$ 
between each stitch (Fig. 15). Therefore, increasing the number of stitches, which is necessary to narrow the gap, is associated with increased risk of tearing of the pancreatic parenchyma, entanglement, and confusion. Therefore, the Kiguchi method should be considered as an ideal new method that overcomes the disadvantages of the invagination method and duct-to-mucosa anastomosis, as a novel hybrid anastomosis method (Fig. 16).

There is no consensus on PJ methods that are better for patients with a soft pancreatic texture because no randomized controlled trials have been limited to patients with a soft pancreatic texture. In OPD, the original Blumgart method has been reported to reduce the rate of POPF in patients with a hard pancreatic texture [30,31]. However, a large-scale retrospective cohort study limited to patients with a soft pancreatic texture reported that there was no significance difference in POPF rate between the modified Kakita method and the modified Blumgart method [32]. In the present report, both methods had a high POPF rate of around $42 \%$. Although duct-to-mucosa anastomosis techniques, such as the Blumgart method, are one of the most widely used PJ approaches, the invagination method is another commonly used technique. In the introduction period of LPD, few studies investigated laparoscopic invagination methods because of issues with technical feasibility [33, 34]. However, superiority of the invagination method to duct-tomucosa anastomosis was obscure because the results were inconsistent among the studies due to different invagination methods used among the study institutions [35-37]. A recent randomized controlled trial in Japan could not demonstrate the superiority of the invagination method to duct-to-mucosa anastomosis based on the rate of POPF; however, the subgroup analysis limited to patients with a soft pancreatic texture revealed that the POPF rate of the invagination method $(10 \%)$ was lower than that of the duct-to-mucosa anastomosis (42\%) and that the invagination method might reduce the risk of POPF compared to duct-to-mucosa anastomosis [38]. In contrast, a large-scale retrospective cohort study in USA limited to patients with a soft pancreatic texture revealed that the POPF rate was significantly higher with the invagination method (38\%) than with duct-to-mucosa anastomosis ( $38 \%$ vs $25 \%$ ) and that ductto-mucosa anastomosis should be considered in patients with a soft pancreatic texture [39]. In a systematic review, the high POPF rate of $26.2 \%$ in patients with a soft pancreatic texture was independent of the type of PJ method used [16]. Other new PJ methods adopted to MIPD have also been proposed [4042]. However, the studies were not limited to patients with a soft pancreatic texture and direct comparison with the present study is difficult. Based on the results of the present study as well as those of past studies, we believe that the Kiguchi method, which combines the invagination method with duct-tomucosa anastomosis, has definitive advantages by simultaneously avoiding technical errors and maximizing water tightness, which greatly contributes to the significant improvement observed in POPF rate.

The present study also revealed that the POPF rates were high at $36.4 \%$ and $42.1 \%$ in the OPD and OldMIPD groups, respectively, in the study cohort comprising only patients with a soft pancreatic texture. These rates, which were very similar to those reported in previous studies, implicate that conventional PJ did not improve the POPF rate despite RPD. Additionally, the duration of hospital stay was significantly shorter in the New-MIPD group than OPD and Old-MIPD group, and the hospital stays longer than one month were clearly related to POPF complications. The present study also confirmed that POPF was the 
most influential factor associated with short-term outcomes. Among the patients without POPF, the hospital stay was significantly shorter in all patients undergoing MIPD than in all patients undergoing OPD, highlighting the benefit of MIPD regardless of the specific PJ method used. The multivariate analysis also revealed that male sex was a significant risk factor for POPF, in agreement with studies showing that male sex is a risk factors for POPF not only in OPD but also in MIPD $[43,44]$. However, the underlying cause requires further investigation.

\section{Consideration of the learning curve}

Regarding the learning curve associated with a new method, the New-MIPD group in the current study represents the initial stage of the learning curve for the Kiguchi method [45]. In fact, one of the study surgeons, IU, has performed MIPD using the Kiguchi method for cases 20-34 and one of the study surgeons, GK, has performed the same procedure for cases 1-11. In the present study, PJ by the Kiguchi method in MIPD was a time-consuming procedure because of the initial stage of the learning curve.

In the present study, the POPF rate in the New-MIPD group during the early learning curve was lower than that in the OPD group, despite the disadvantages associated with the learning curve, indirectly suggesting that the new anastomosis design of the Kiguchi method contributes to the reduction in POPF rate especially in patients with a soft pancreatic texture.

\section{Study limitations}

The present study has several limitations. First, although limited only to patients with a soft pancreas, which has been shown to be closely related to higher POPF rates, this was not a prospective, randomized study and the results might have been affected by several biases and the small sample size. Specifically, regarding comparisons between the New-MIPD and Old-MIPD groups, the observation period was different between the groups and the bias in technical aspects could not be denied because the Kiguchi method was designed with consideration of the technical issues faced in conventional PJ that was used in the Old-MIPD group. However, the Kiguchi method was clearly associated with a significantly reduced POPF rate in patients undergoing MIPD. This study could not evaluate the difference between LPD and the RPD. Given that the PJ method was almost the same between LPD and the RPD in the New-MIPD group, the significant reduction in POPF rate observed in the present study was likely related to the difference in PJ method and not to the use of a robot. Second, as the study cohort was confined to patients with a soft pancreatic texture, the significance of the Kiguchi method in those with a hard pancreatic texture, which tends to be accompanied with a larger pancreatic duct, was not evaluated. However, we have already developed a new modified PJ method, the Kiguchi method version 2, suitable for such situations. Finally, the safety and feasibility of the Kiguchi method for PJ in MIPD should be verified by prospective randomized controlled trials in near future.

\section{Conclusion}


The Kiguchi method not only facilitates PJ in MIPD but also is expected to significantly improve POPF rate especially in patients with a soft pancreatic texture. Prospective randomized controlled trials are necessary to validate the superiority of the Kiguchi method.

\section{Abbreviations}

$\mathrm{Cl}$, confidence interval; ISGPS, International Study Group on Pancreatic Surgery; LPD, laparoscopic pancreaticoduodenectomy; MIPD, minimally invasive pancreaticoduodenectomy; OPD, open pancreaticoduodenectomy; OR, odds ratio; PD, pancreaticoduodenectomy; PJ, pancreaticojejunostomy, POPF, postoperative pancreatic fistula; RPD, robotic pancreaticoduodenectomy

\section{Declarations}

\section{Ethics approval and consent to participate}

All procedures performed in studies involving human participants were in accordance with the ethical standards of the institutional and/or national research committee (Fujita Health University Certified Clinical Research Review Board, approval number: HM19-064) and with the 1964 Helsinki declaration and its later amendments or comparable ethical standards. Written informed consent was obtained from all patients in accordance with the ethical guidelines of Fujita Health University.

\section{Consent for publication}

All patients provided written consent for their personal or clinical details along with any identifying images to be published in this study.

\section{Availability of data and materials}

The datasets used and analyzed during this study are available from the corresponding author on reasonable request.

\section{Competing interests}

The authors declare that they have no competing interests.

\section{Funding:}

This research did not receive any specific grant from funding agencies in the public, commercial, or notfor-profit sectors.

\section{Authors' contributions}

GK conceived and design the study. GK wrote the manuscript text. AS edited the manuscript. GK, MK and AY collection and assembly data. GK and MN data analysis and interpretation. All authors read and 
approved the final manuscript.

\section{Acknowledgments}

The authors are indebted to Maruzen CO., LTD. (Tokyo, Japan) for their native English speaker's review of this manuscript.

\section{References}

1. Yekebas EF, Wolfram L, Cataldegirmen G, Habermann CR, Bogoevski D, Koenig AM, et al. Postpancreatectomy hemorrhage: diagnosis and treatment: an analysis in 1669 consecutive pancreatic resections. Ann Surg. 2007;246(2):269-80.

2. Pratt WB, Maithel SK, Vanounou T, Huang ZS, Callery MP, Vollmer CM Jr. Clinical and economic validation of the International Study Group of Pancreatic Fistula (ISGPF) classification scheme. Ann Surg. 2007;245(3):443-51.

3. Fuks D, Piessen G, Huet E, Tavernier M, Zerbib P, Michot F, et al. Life-threatening postoperative pancreatic fistula (grade $\mathrm{C}$ ) after pancreaticoduodenectomy: incidence, prognosis, and risk factors. Am J Surg. 2009;197(6):702-9.

4. Cameron JL, Riall TS, Coleman J, Belcher KA. One thousand consecutive pancreaticoduodenectomies. Ann Surg. 2006;244(1):10-5.

5. Kawai M, Kondo S, Yamaue H, Wada K, Sano K, Motoi F, et al. Predictive risk factors for clinically relevant pancreatic fistula analyzed in 1,239 patients with pancreaticoduodenectomy: multicenter data collection as a project study of pancreatic surgery by the Japanese Society of Hepato-BiliaryPancreatic Surgery. J Hepatobiliary Pancreat Sci. 2011;18(4):601-8.

6. El Nakeeb A, Salah T, Sultan A, El Hemaly M, Askr W, Ezzat H, et al. Pancreatic anastomotic leakage after pancreaticoduodenectomy. Risk factors, clinical predictors, and management (single center experience). World J Surg. 2013;37(6):1405-18.

7. Callery MP, Pratt WB, Kent TS, Chaikof EL, Vollmer CM. Jr. A prospectively validated clinical risk score accurately predicts pancreatic fistula after pancreatoduodenectomy. J Am Coll Surg. 2013;216(1):114.

8. Ecker BL, McMillan MT, Asbun HJ, Ball CG, Bassi C, Beane JD, et al. Characterization and Optimal Management of High-risk Pancreatic Anastomoses During Pancreatoduodenectomy. Ann Surg. 2018;267(4):608-16.

9. Huang MJ, Liang JL, Wang H, Kang L, Deng YH, Wang JP. Laparoscopic-assisted versus open surgery for rectal cancer: a meta-analysis of randomized controlled trials on oncologic adequacy of resection and long-term oncologic outcomes. Int J Colorectal Dis. 2011;26(4):415-21.

10. Ohtani H, Tamamori Y, Azuma T, Mori Y, Nishiguchi Y, Maeda K, et al. A meta-analysis of the shortand long-term results of randomized controlled trials that compared laparoscopy-assisted and conventional open surgery for rectal cancer. J Gastrointest Surg. 2011;15(8):1375-85. 
11. Yang Y, Wang G, He J, Wu F, Ren S. Robotic gastrectomy versus open gastrectomy in the treatment of gastric cancer. J Cancer Res Clin Oncol. 2017;143(1):105-14.

12. Boggi U, Amorese G, Vistoli F, Caniglia F, De Lio N, Perrone V, et al. Laparoscopic pancreaticoduodenectomy: a systematic literature review. Surg Endosc. 2015;29(1):9-23.

13. Adam MA, Choudhury K, Dinan MA, Reed SD, Scheri RP, Blazer DG 3. Minimally Invasive Versus Open Pancreaticoduodenectomy for Cancer: Practice Patterns and Short-term Outcomes Among 7061 Patients. Ann Surg. 2015;262(2):372-7. rd, et al.

14. van Hilst J, de Rooij T, Bosscha K, Brinkman DJ, van Dieren S, Dijkgraaf MG, et al. Laparoscopic versus open pancreatoduodenectomy for pancreatic or periampullary tumours (LEOPARD-2): a multicentre, patient-blinded, randomised controlled phase 2/3 trial. The lancet Gastroenterology hepatology. 2019;4(3):199-207.

15. Kendrick ML, van Hilst J, Boggi U, de Rooij T, Walsh RM, Zeh HJ, et al. Minimally invasive pancreatoduodenectomy. HPB (Oxford). 2017;19(3):215-24.

16. Eshmuminov D, Schneider MA, Tschuor C, Raptis DA, Kambakamba P, Muller X, et al. Systematic review and meta-analysis of postoperative pancreatic fistula rates using the updated 2016 International Study Group Pancreatic Fistula definition in patients undergoing pancreatic resection with soft and hard pancreatic texture. HPB. 2018;20(11):992-1003.

17. Panni RZ, Guerra J, Hawkins WG, Hall BL, Asbun HJ, Sanford DE. National Pancreatic Fistula Rates after Minimally Invasive Pancreaticoduodenectomy: A NSQIP Analysis. J Am Coll Surg. 2019;229(2):192. -9.e191.

18. Kiguchi G, Sugioka A, Kato Y, Uyama I. Use of a novel semi-derotation technique for artery-first approach in laparoscopic pancreaticoduodenectomy. Surg Oncol. 2020;33:141-2.

19. Kakita A, Takahashi T, Yoshida M, Furuta K. A simpler and more reliable technique of pancreatojejunal anastomosis. Surg Today. 1996;26(7):532-5.

20. Fujii T, Sugimoto H, Yamada S, Kanda M, Suenaga M, Takami H, et al. Modified Blumgart anastomosis for pancreaticojejunostomy: technical improvement in matched historical control study. J Gastrointest Surg. 2014;18(6):1108-15.

21. Dindo D, Demartines N, Clavien PA. Classification of surgical complications: a new proposal with evaluation in a cohort of 6336 patients and results of a survey. Ann Surg. 2004;240(2):205-13.

22. Bassi C, Marchegiani G, Dervenis C, Sarr M, Abu Hilal M, Adham M, et al. The 2016 update of the International Study Group (ISGPS) definition and grading of postoperative pancreatic fistula: 11 Years After. Surgery. 2017;161(3):584-91.

23. Wente MN, Veit JA, Bassi C, Dervenis C, Fingerhut A, Gouma DJ, et al. Postpancreatectomy hemorrhage (PPH): an International Study Group of Pancreatic Surgery (ISGPS) definition. Surgery. 2007;142(1):20-5.

24. Wente MN, Bassi C, Dervenis C, Fingerhut A, Gouma DJ, Izbicki JR, et al. Delayed gastric emptying (DGE) after pancreatic surgery: a suggested definition by the International Study Group of Pancreatic Surgery (ISGPS). Surgery. 2007;142(5):761-8. 
25. Sugimoto M, Takahashi S, Kojima M, Kobayashi T, Gotohda N, Konishi M. In Patients with a Soft Pancreas, a Thick Parenchyma, a Small Duct, and Fatty Infiltration Are Significant Risks for Pancreatic Fistula After Pancreaticoduodenectomy. J Gastrointest Surg. 2017;21(5):846-54.

26. Lin JW, Cameron JL, Yeo CJ, Riall TS, Lillemoe KD. Risk factors and outcomes in postpancreaticoduodenectomy pancreaticocutaneous fistula. J Gastrointest Surg. 2004;8(8):951-9.

27. Pratt WB, Callery MP, Vollmer CM. Jr. Risk prediction for development of pancreatic fistula using the ISGPF classification scheme. World J Surg. 2008;32(3):419-28.

28. Ansorge C, Strommer L, Andren-Sandberg A, Lundell L, Herrington MK, Segersvard R. Structured intraoperative assessment of pancreatic gland characteristics in predicting complications after pancreaticoduodenectomy. Br J Surg. 2012;99(8):1076-82.

29. Poves I, Morato O, Burdio F, Grande L. Laparoscopic-adapted Blumgart pancreaticojejunostomy in laparoscopic pancreaticoduodenectomy. Surg Endosc. 2017;31(7):2837-45.

30. Kleespies A, Rentsch M, Seeliger H, Albertsmeier M, Jauch KW, Bruns CJ. Blumgart anastomosis for pancreaticojejunostomy minimizes severe complications after pancreatic head resection. Br J Surg. 2009;96(7):741-50.

31. Grobmyer SR, Kooby D, Blumgart LH, Hochwald SN. Novel pancreaticojejunostomy with a low rate of anastomotic failure-related complications. J Am Coll Surg. 2010;210(1):54-9.

32. Kawakatsu S, Inoue Y, Mise Y, Ishizawa T, Ito H, Takahashi Y, et al. Comparison of pancreatojejunostomy techniques in patients with a soft pancreas: Kakita anastomosis and Blumgart anastomosis. BMC Surg. 2018;18(1):88.

33. Palanivelu C, Jani K, Senthilnathan P, Parthasarathi R, Rajapandian S, Madhankumar MV. Laparoscopic pancreaticoduodenectomy: technique and outcomes. J Am Coll Surg. 2007;205(2):222-30.

34. Cho A, Yamamoto H, Kainuma O, Muto Y, Park S, Arimitsu H, et al. Performing simple and safe dunking pancreaticojejunostomy using mattress sutures in pure laparoscopic pancreaticoduodenectomy. Surg Endosc. 2014;28(1):315-8.

35. Berger AC, Howard TJ, Kennedy EP, Sauter PK, Bower-Cherry M, Dutkevitch S, et al. Does type of pancreaticojejunostomy after pancreaticoduodenectomy decrease rate of pancreatic fistula? A randomized, prospective, dual-institution trial. J Am Coll Surg. 2009;208(5):738-47. discussion 7479.

36. Bai X, Zhang Q, Gao S, Lou J, Li G, Zhang Y, et al. Duct-to-Mucosa vs Invagination for Pancreaticojejunostomy after Pancreaticoduodenectomy: A Prospective, Randomized Controlled Trial from a Single Surgeon. J Am Coll Surg. 2016;222(1):10-8.

37. El Nakeeb A, El Hemaly M, Askr W, Abd Ellatif M, Hamed H, Elghawalby A, et al. Comparative study between duct to mucosa and invagination pancreaticojejunostomy after pancreaticoduodenectomy: A prospective randomized study. Int J Surg. 2015;16:1-6.

38. Senda Y, Shimizu Y, Natsume S, Ito S, Komori K, Abe T, et al. Randomized clinical trial of duct-tomucosa versus invagination pancreaticojejunostomy after pancreatoduodenectomy. Br J Surg. 
2018;105(1):48-57.

39. Rivas L, Zettervall SL, Ju T, Olafson S, Holzmacher J, Lin PP, et al. The Effect of Pancreaticojejunostomy Technique on Fistula Formation Following Pancreaticoduodenectomy in the Soft Pancreas. J Gastrointest Surg. 2019;23(11):2211-5.

40. Wang M, Xu S, Zhang H, Peng S, Zhu F, Qin R. Imbedding pancreaticojejunostomy used in pure laparoscopic pancreaticoduodenectomy for nondilated pancreatic duct. Surg Endosc. 2017;31(4):1986-92.

41. Cai Y, Luo H, Li Y, Gao P, Peng B. A novel technique of pancreaticojejunostomy for laparoscopic pancreaticoduodenectomy. Surg Endosc. 2019;33(5):1572-7.

42. Liu Q, Zhao Z, Gao Y, Zhao G, Tan X, Wang C, et al. Novel single-layer continuous suture of pancreaticojejunostomy for robotic pancreaticoduodenectomy. J Hepatobiliary Pancreat Sci. 2020;27(2):56-63.

43. Ellis RJ, Brock Hewitt D, Liu JB, Cohen ME, Merkow RP, Bentrem DJ, et al. Preoperative risk evaluation for pancreatic fistula after pancreaticoduodenectomy. J Surg Oncol. 2019;119(8):1128-34.

44. Mungroop TH, Klompmaker S, Wellner UF, Steyerberg EW, Coratti A, D'Hondt M, et al. Updated Alternative Fistula Risk Score (ua-FRS) to Include Minimally Invasive Pancreatoduodenectomy: PanEuropean Validation. Ann Surg. 2019.

45. Watkins AA, Kent TS, Gooding WE, Boggi U, Chalikonda S, Kendrick ML, et al. Multicenter outcomes of robotic reconstruction during the early learning curve for minimally-invasive pancreaticoduodenectomy. HPB (Oxford). 2018;20(2):155-65.

\section{Tables}

Due to technical limitations, table 1 to 5 is only available as a download in the Supplemental Files section.

\section{Figures}




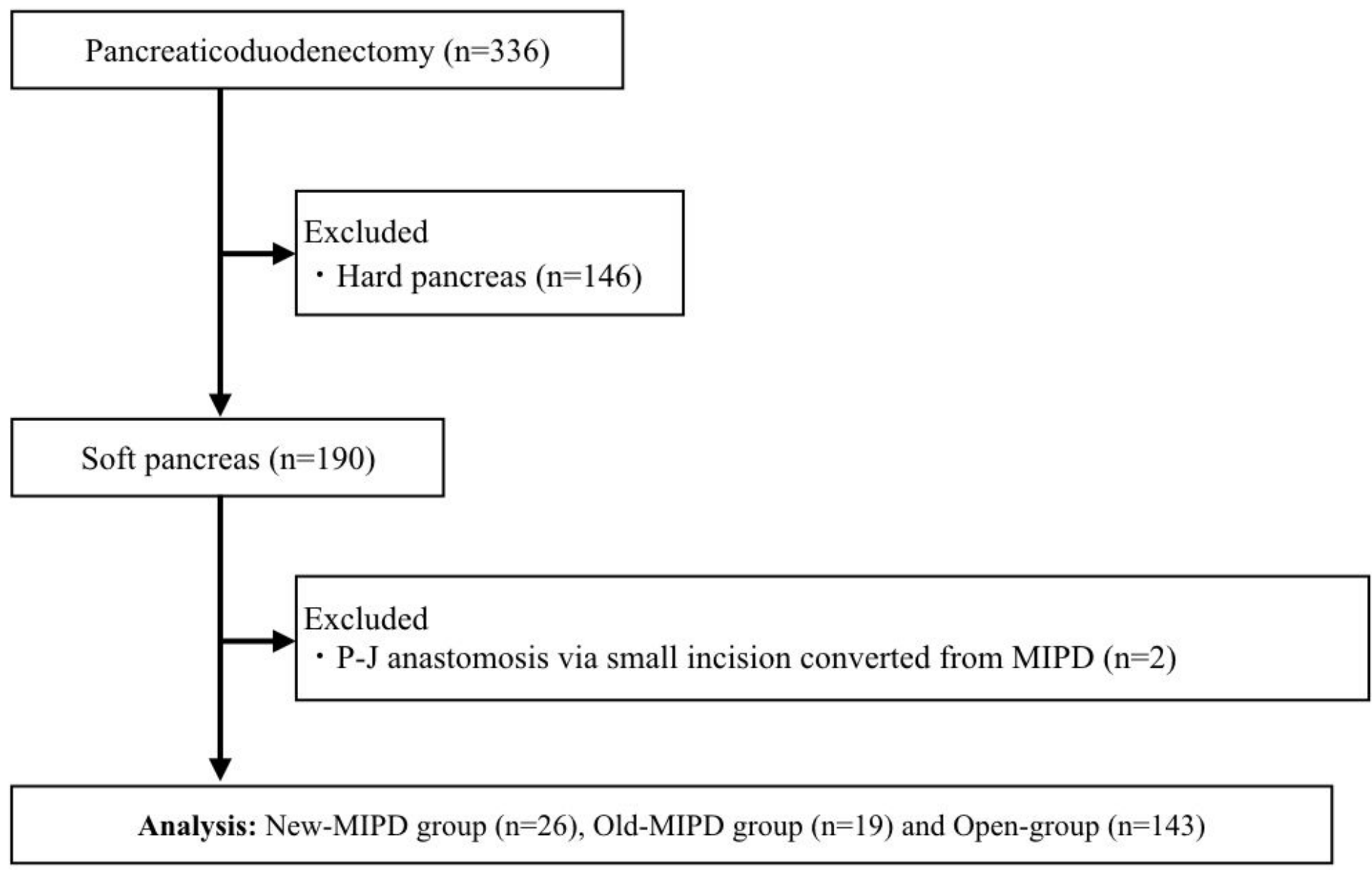

Figure 1

Flowchart of patient allocation 


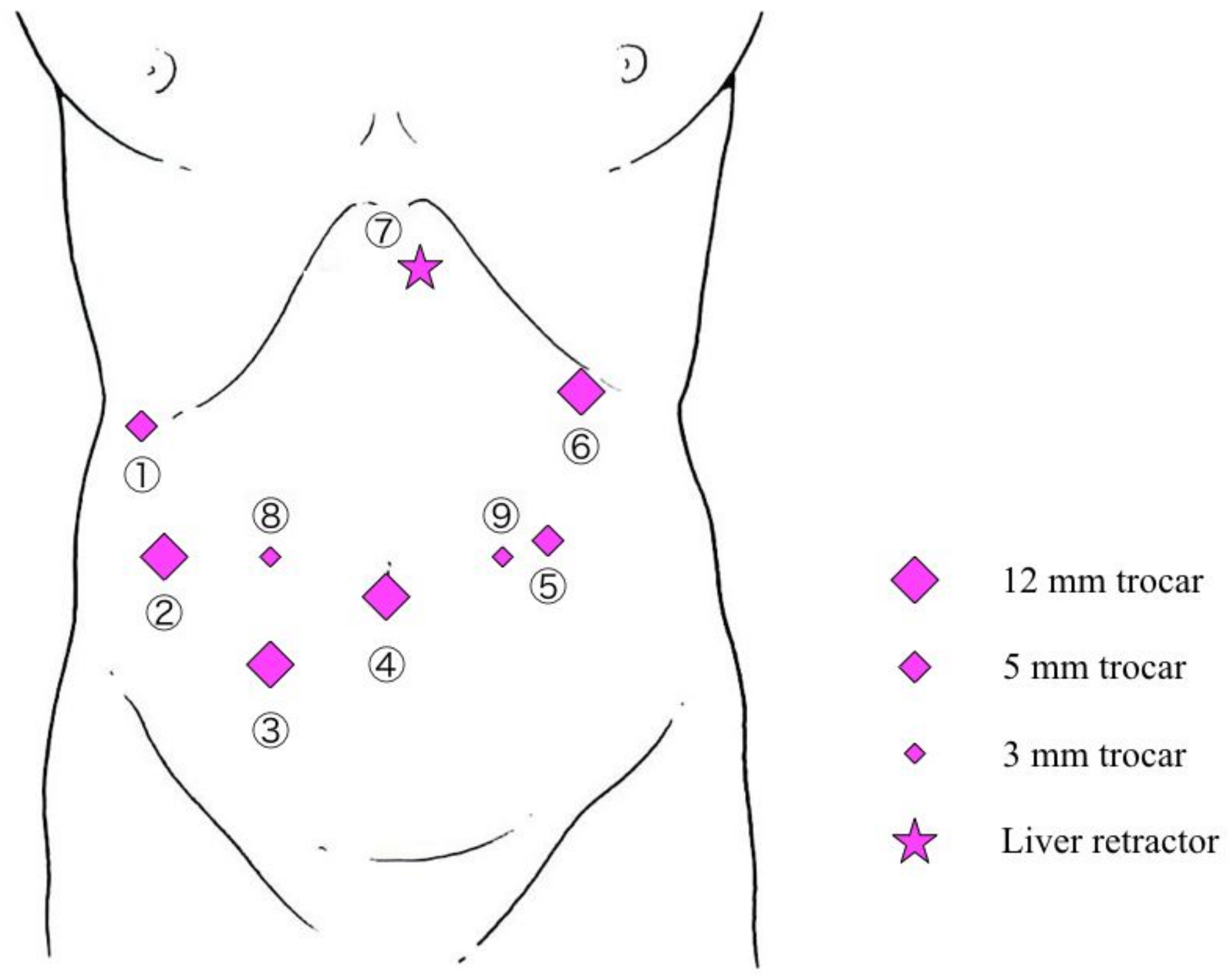

Figure 2

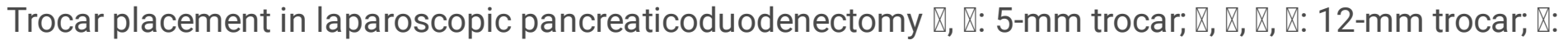

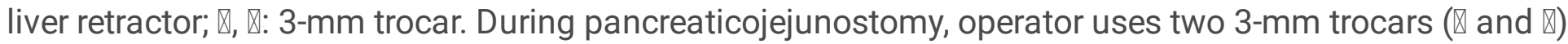
and camera assistant uses a 12-mm trocar $(\mathbb{\nabla})$. Outer-layer sutures are temporarily externalized through a 12-mm trocar (囚). 


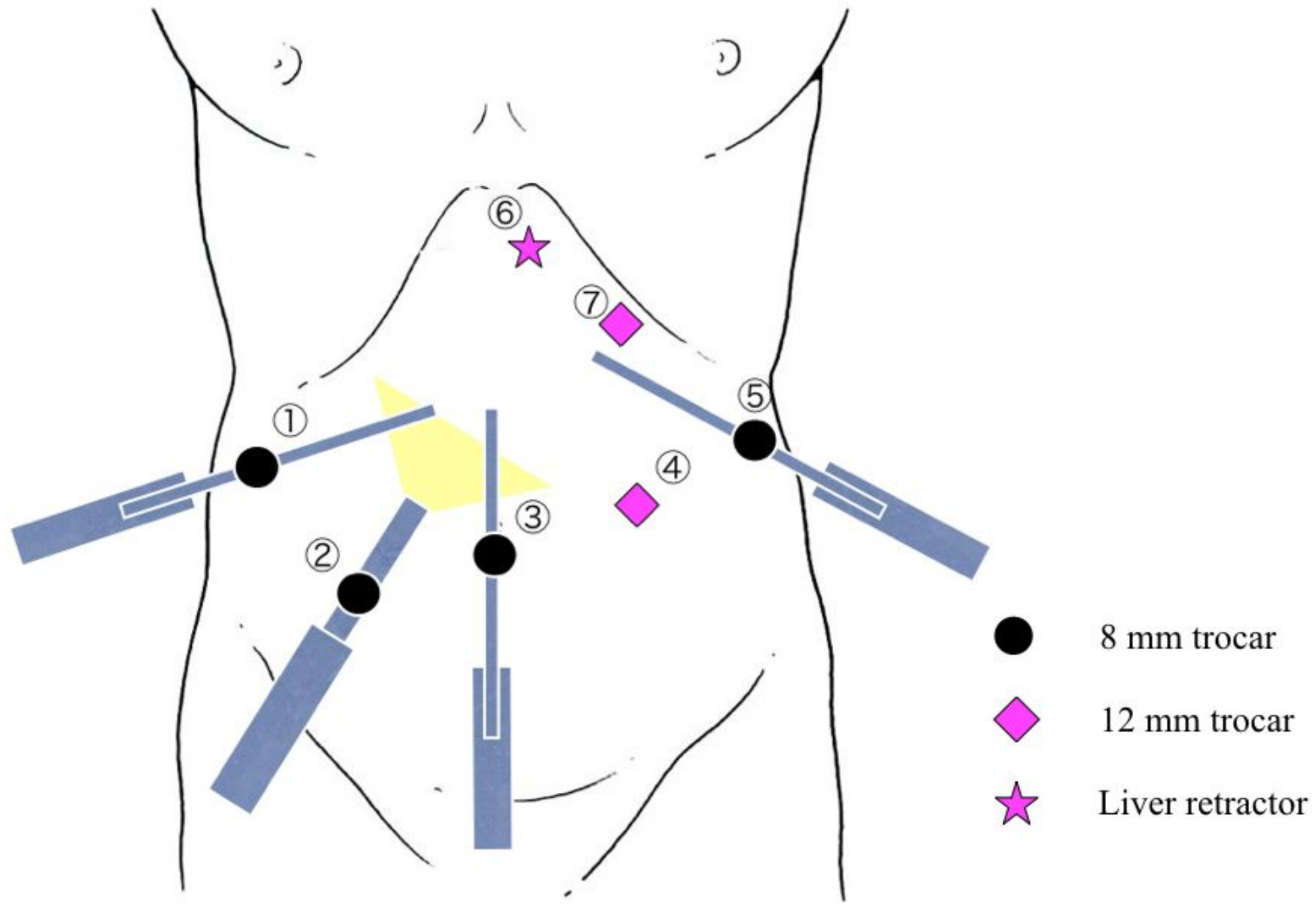

Figure 3

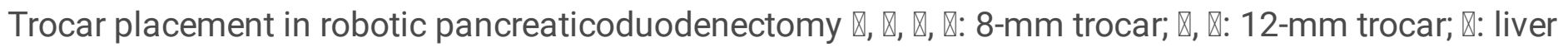
retractor. During pancreaticojejunostomy, operator uses first arm from trocar $\nabla$, third arm from trocar $\nabla$,

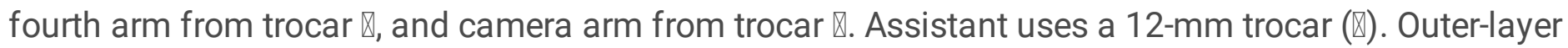

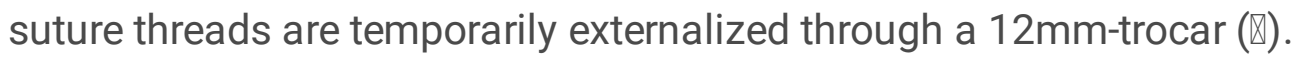




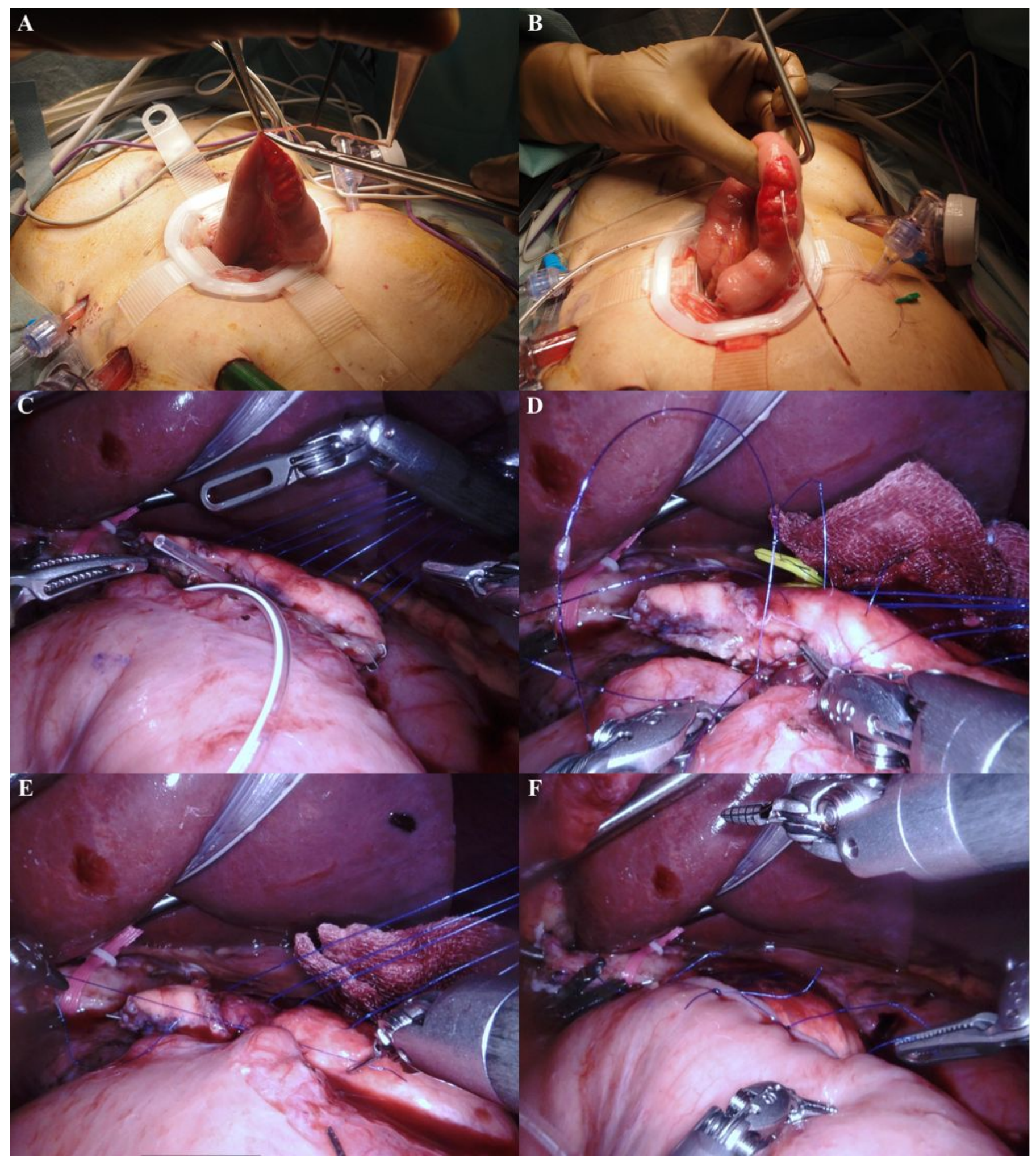

\section{Figure 4}

Pancreaticojejunostomy using the Kiguchi method A. In extracorporeal maneuver, a seromuscular incision is created on the jejunal wall where the pancreatic stump will be in contact. B. After the creation of seromuscular incision and insertion of the pancreatic duct tube, two 12-cm 5-0 polydioxanone sutures are ligated and fixed to the pancreatic duct tube. C. It is critical to prevent the entanglement of suture threads by pulling out of body from the port just above the pancreas after placing the transpancreatic 
sutures. D. In robotic surgery, articulated forceps are used, but needle movement in sagittal direction perpendicular to the axis of the forceps is optimal. E. During ligation of inner-layer sutures, pulling the outer-layer suture threads from outside the body allows the remnant pancreas and jejunum loop to adhere together, enabling stable ligation. F. Completion of pancreaticojejunostomy using the Kiguchi method.

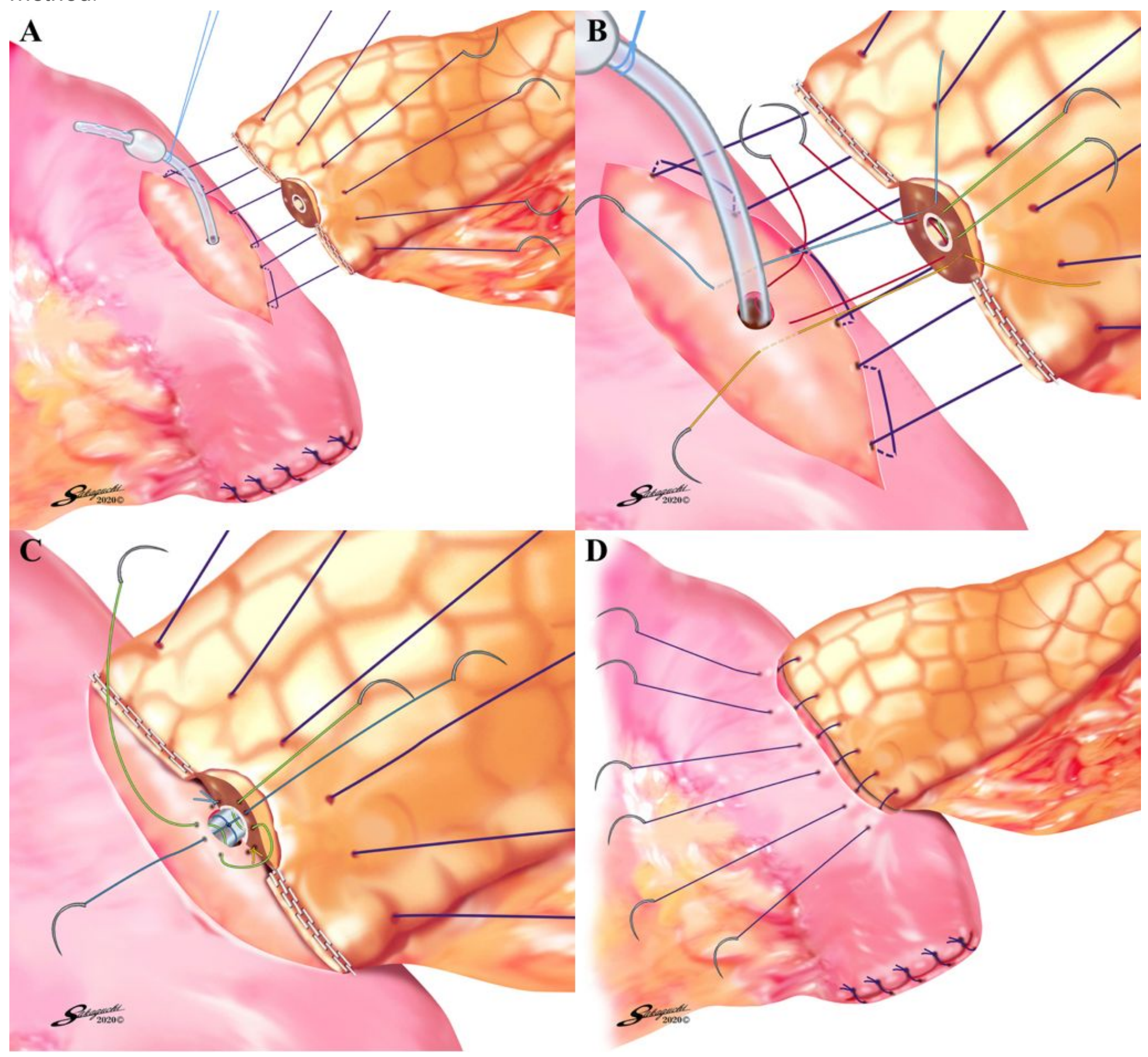

\section{Figure 5}

Mode chart of pancreaticojejunostomy using the Kiguchi method A. Seromuscular incision of the jejunal loop is made with an extracorporeal maneuver. With horizontal mattress sutures using three doubleended needles, outer-layer sutures are placed from the dorsal side of jejunum and through pancreatic parenchyma and externalized through the trocar. B. Five inner-layer sutures are placed including one 
anchor thread of the pancreatic duct tube. Two horizontal mattress sutures are placed on the ventral and dorsal sides through the main pancreatic duct, and two single interrupted sutures are placed on the cranial and caudal sides of main pancreatic duct without passing through the lumen of main pancreatic duct. C. After inserting and fixing the pancreatic duct tube, the horizontal mattress suture on the ventral is ligated. D. The Kiguchi method is completed by stitching and ligating the outer-layer threads on the ventral edge of the seromuscular incision in a horizontal mattress fashion.

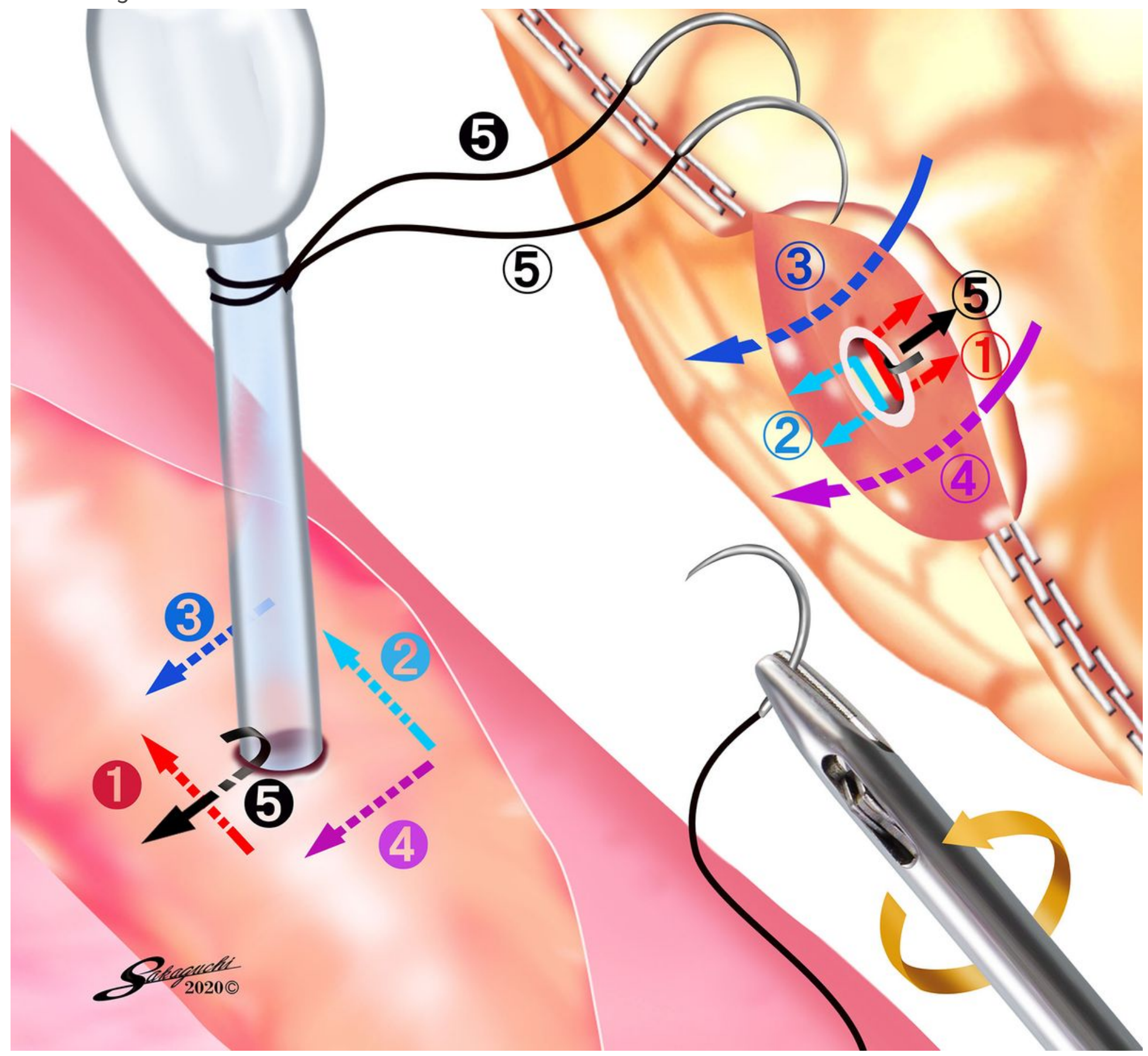

Figure 6

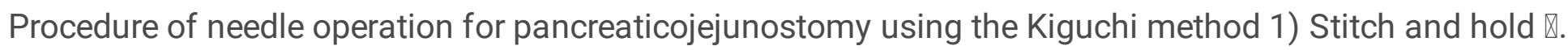

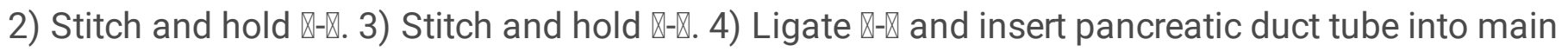

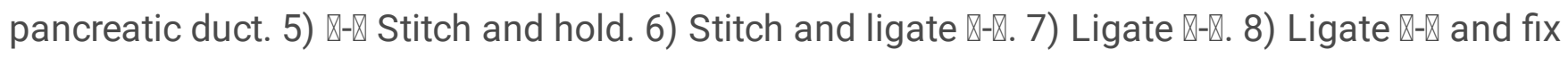


pancreatic duct tube. 9) Stitch $\otimes$ and ligate $\mathbb{\nabla} \nabla$. It is important to have a procedure in which the threads before ligation are not easily entangled and to ascertain that the subsequent ligation will not hinder the next needle movement.

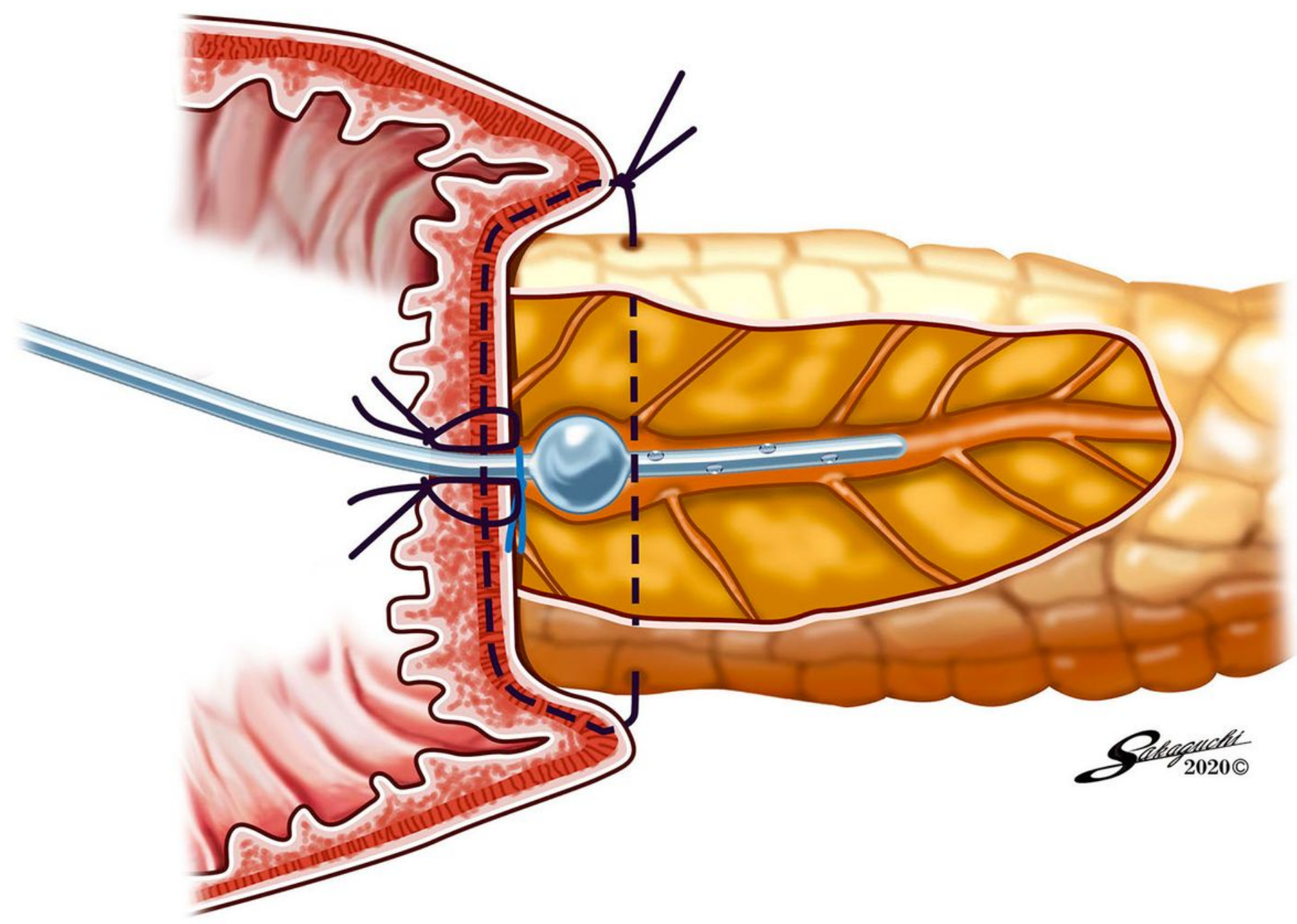

Figure 7

Modified Kakita method from vertical sectional view Several interrupted sutures are placed for outer-layer sutures through the pancreatic parenchyma and jejunal seromuscular layer. 


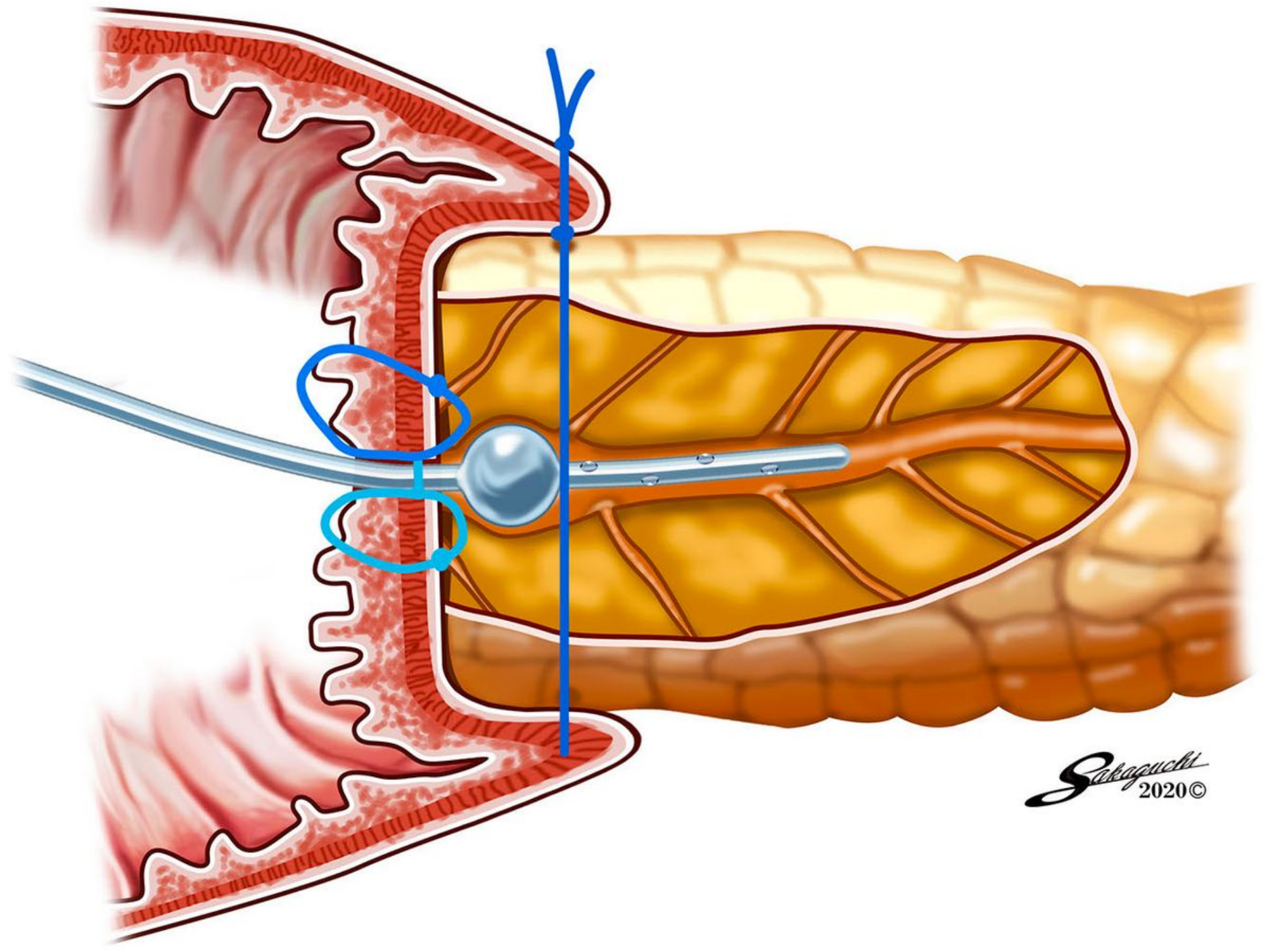

Figure 8

The Blumgart method from vertical sectional view Several horizontal mattress sutures are placed for outer-layer sutures through the pancreatic parenchyma and jejunal seromuscular layer. 


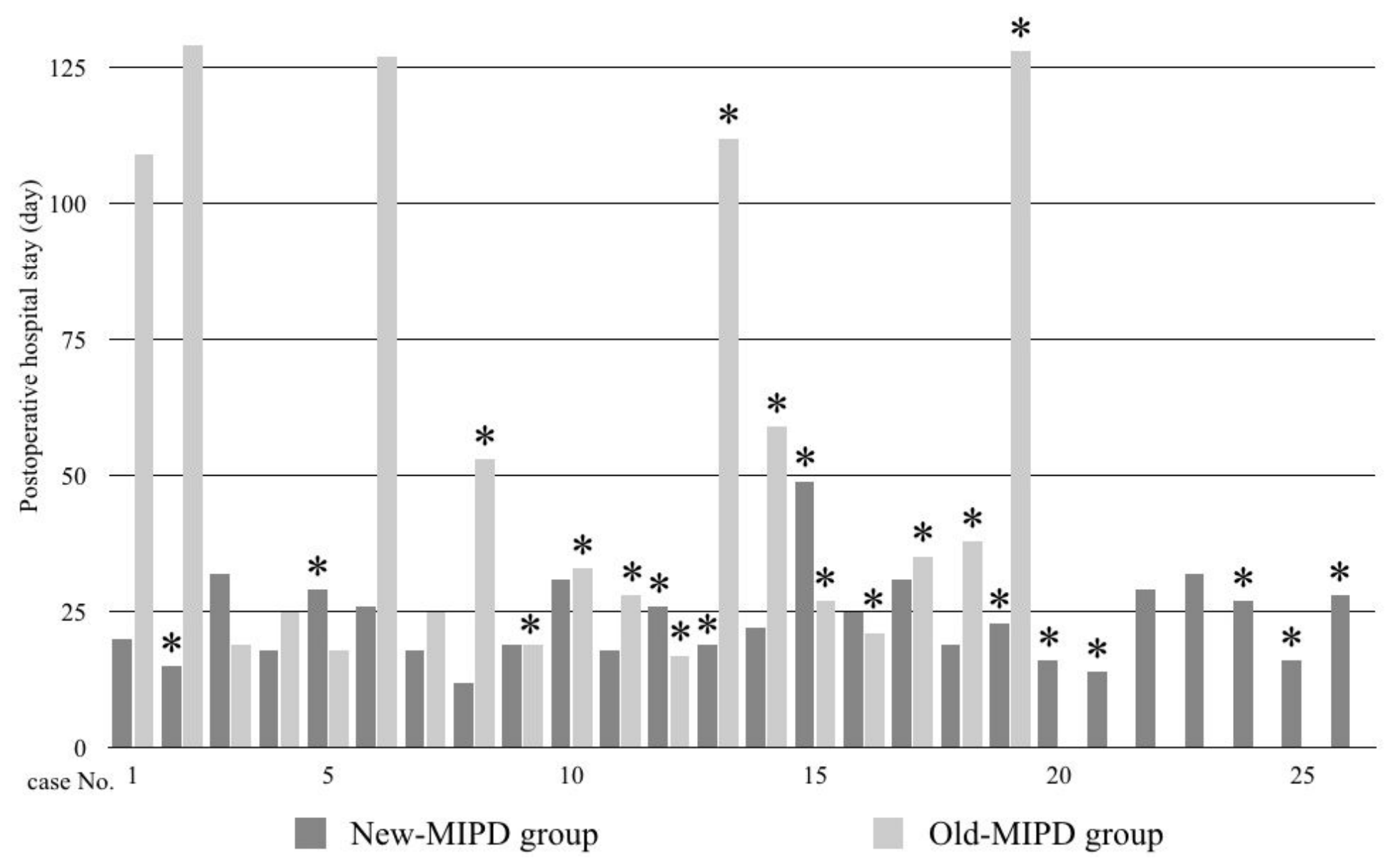

Figure 9

Postoperative hospital stays in the new and old minimally invasive pancreaticoduodenectomy (MIPD) groups 


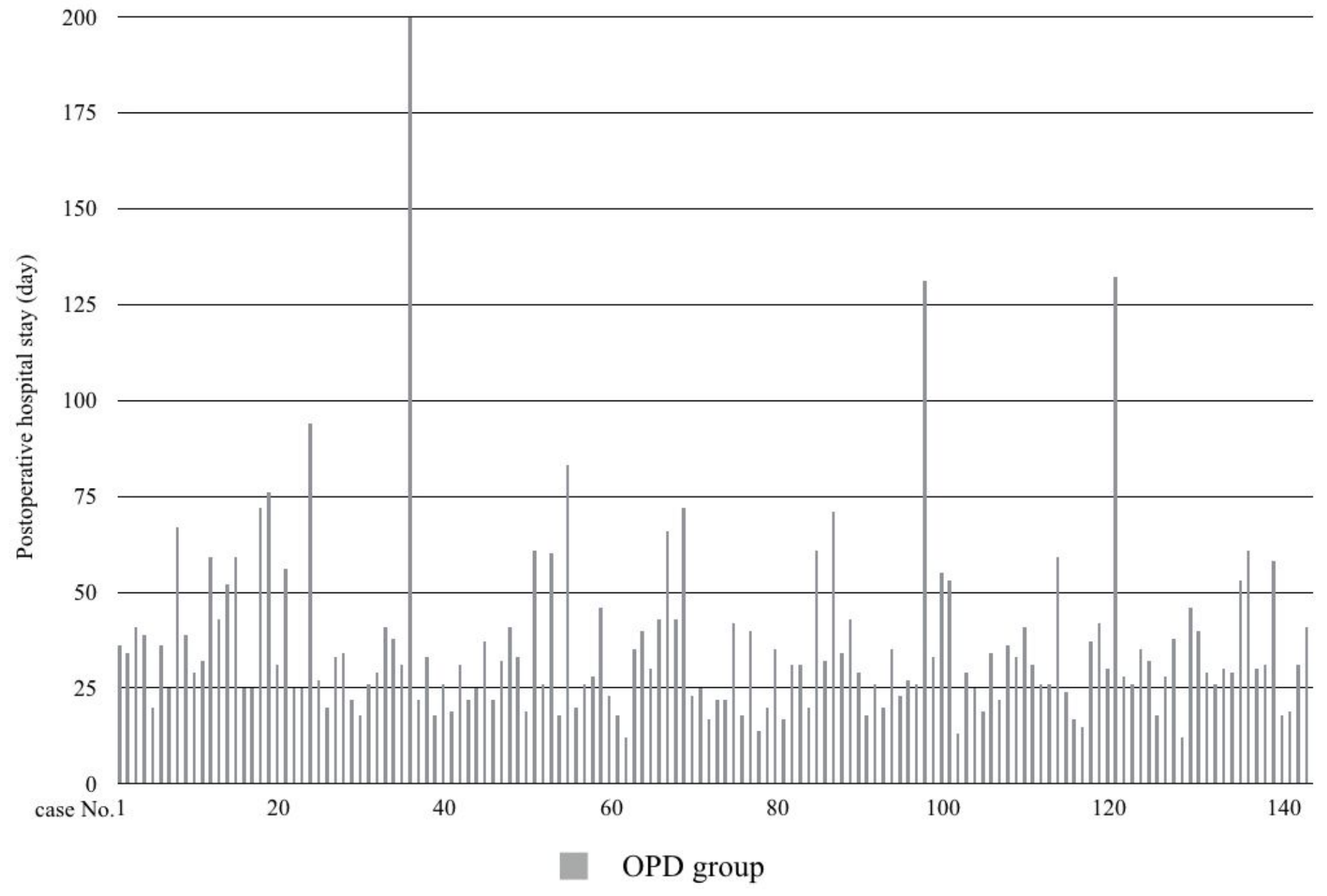

Figure 10

Postoperative hospital stay in the open pancreaticoduodenectomy (OPD) group 


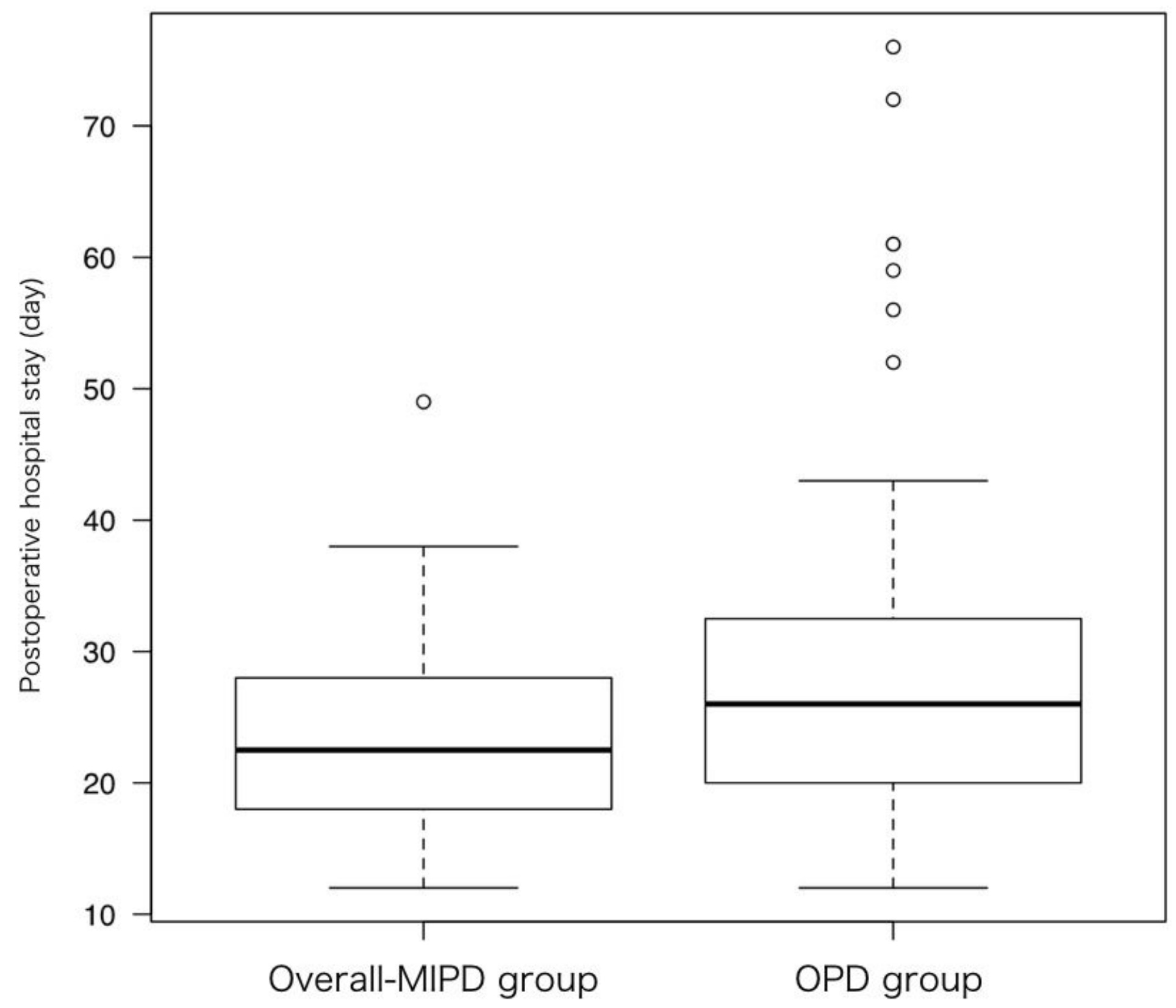

Figure 11

Comparison of postoperative hospital stay of cases without postoperative pancreatic fistula between the overall-MIPD and OPD groups 
Causes of POPF

Improvements in Kiguchi-method
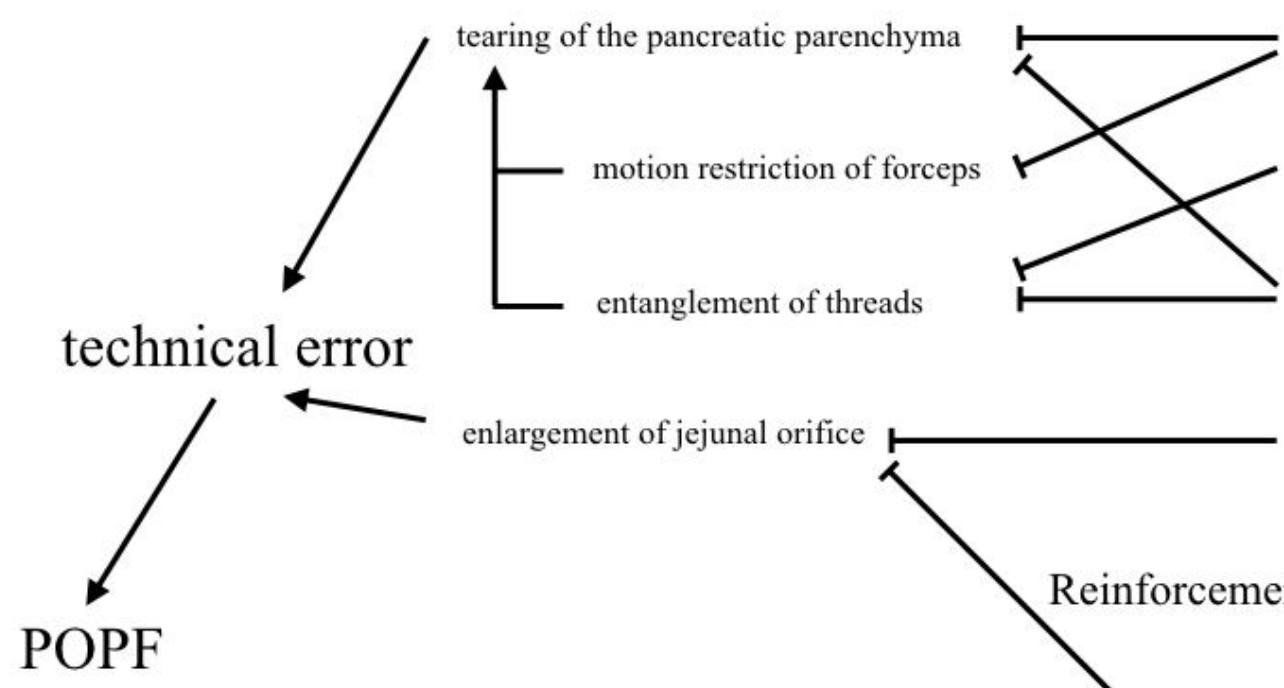

stitches only in vertical direction

reduction in thread number

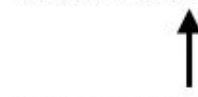

horizontal mattress suture

enlargement of jejunal orifice

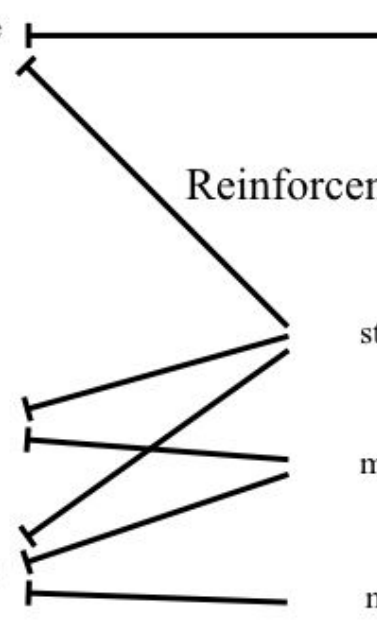

avoiding passing through the jejunal orifice

hes placed in square for inner layer sutures

maximum size of pancreatic duct tube

minimum orifice of jejunal loop

pancreatic stump transected by auto-suturing device

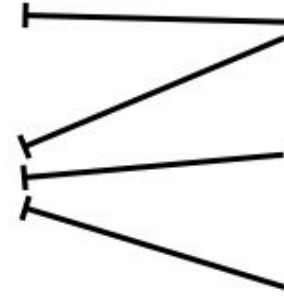

invagination covered by seromuscular-excised area

horizontal mattress suture of outer layer

Figure 12

Technical improvement in the Kiguchi method for prevention of postoperative pancreatic fistula (POPF) 


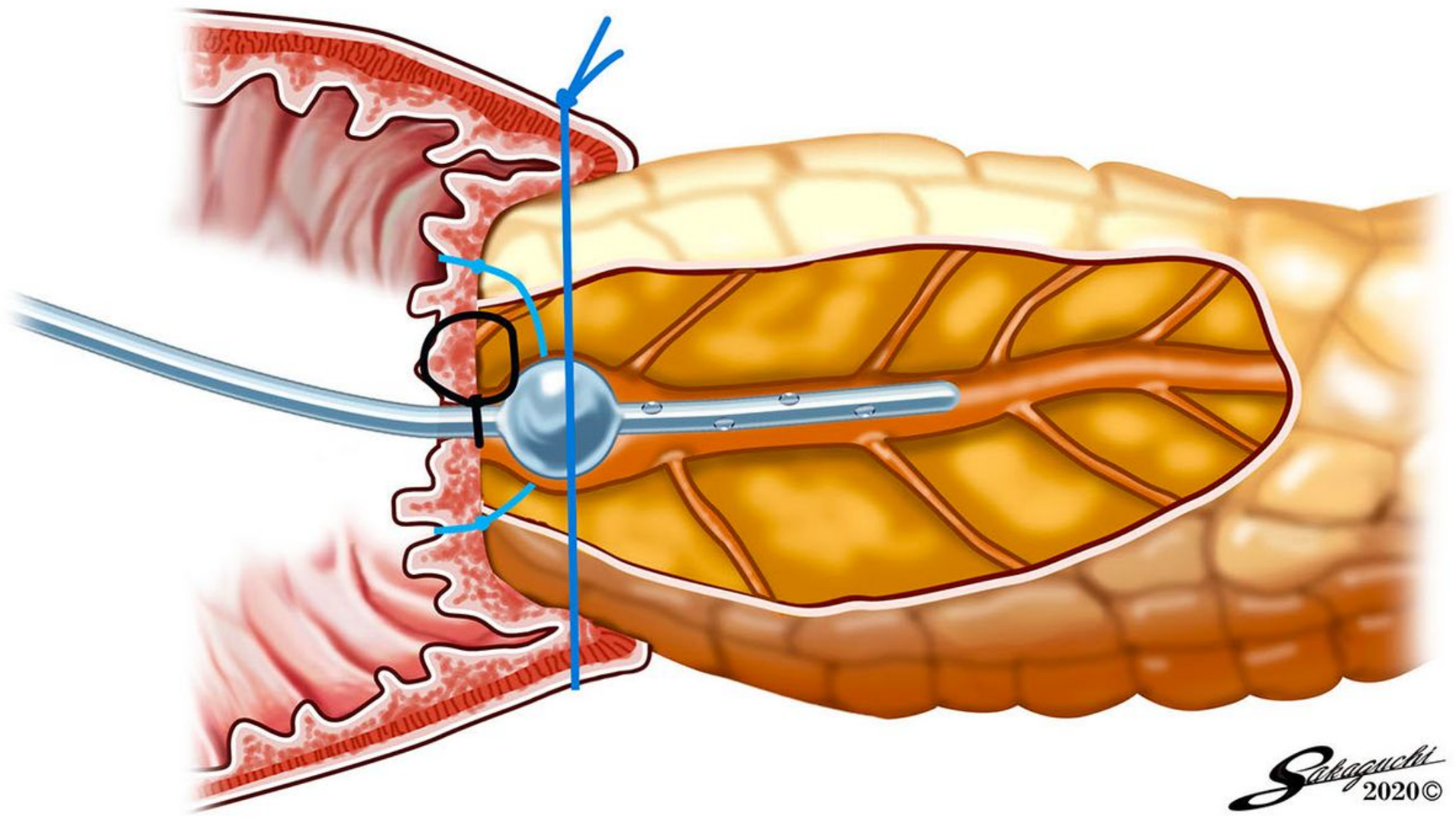

Figure 13

The Kiguchi method from vertical sectional view In the Kiguchi method, seromuscular incision on the jejunum side and the transpancreatic sutures placed in a horizontal mattress fashion allow the jejunal wall to adhere to the remnant pancreas without excessive tension. The seromuscular incision allows the pancreatic stump to invaginate into the lumen of jejunal loop while separating from the lumen. 


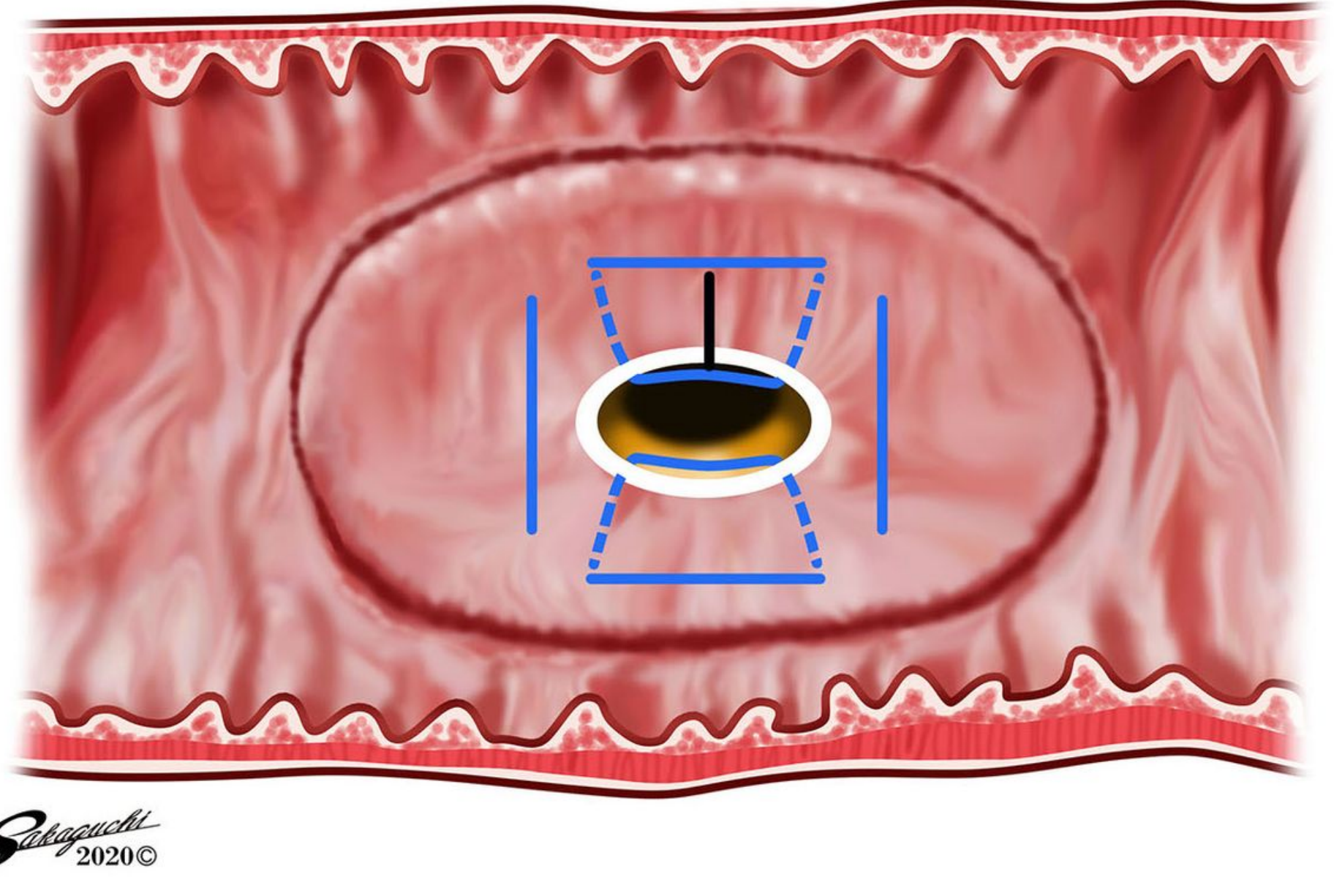

\section{Figure 14}

The Kiguchi method from view of the jejunal lumen side In the Kiguchi method, four stitches are placed in a square pattern to surround the main pancreatic duct. The needle movement to the main pancreatic duct and pancreatic stump is limited to the sagittal direction only. The gap between stitches is only around the vertices of stitches placed in a square pattern. 


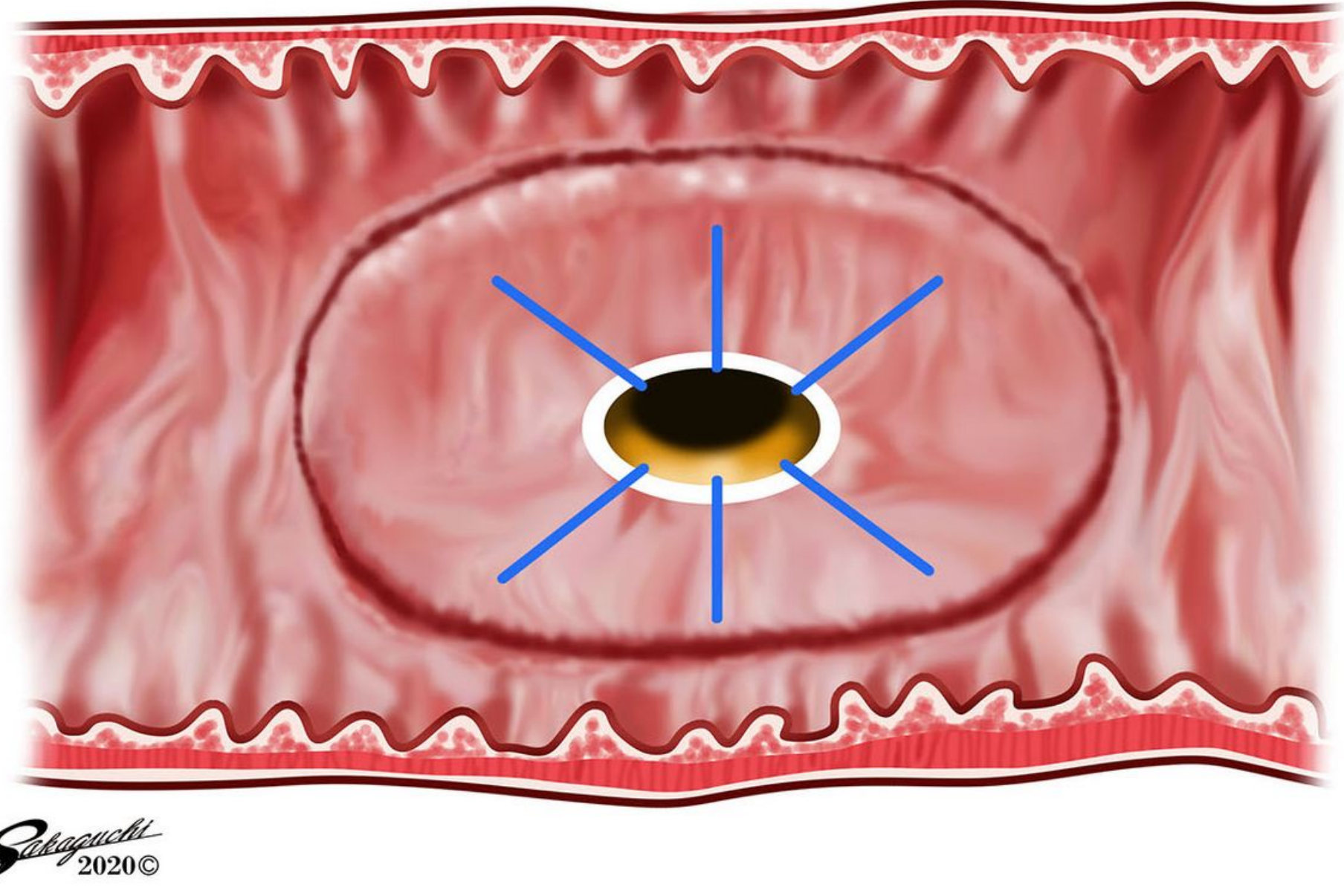

\section{Figure 15}

Conventional pancreaticojejunostomy from view of the jejunal lumen side In conventional duct-tomucosa pancreaticojejunostomy, single interrupted stitches are placed around the main pancreatic duct in a radial direction. This method creates a gap between the radial stitches around the main pancreatic duct. 


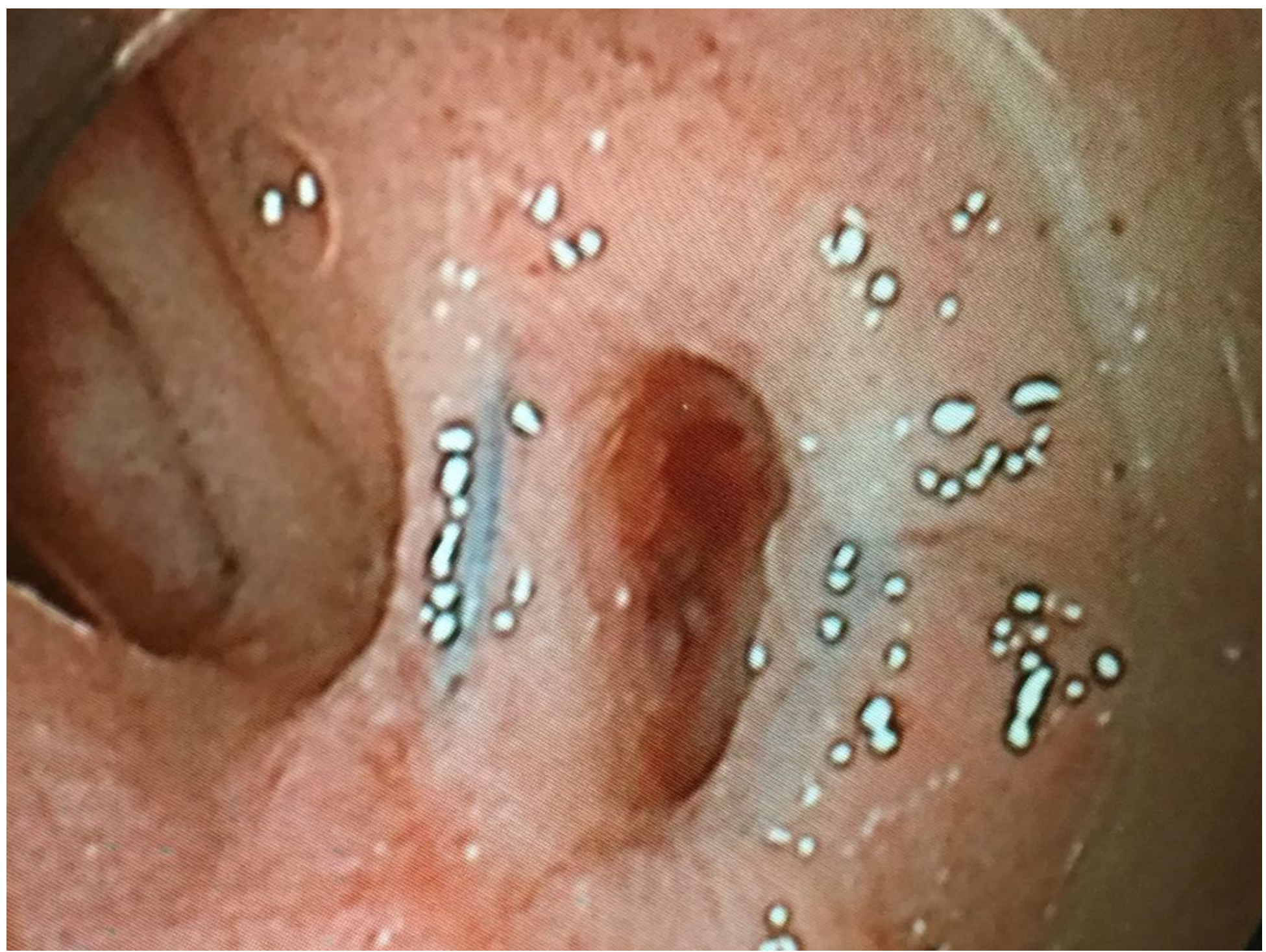

Figure 16

Endoscopic findings of pancreaticojejunostomy using the Kiguchi method Endoscopic findings of pancreaticojejunostomy using the Kiguchi method are similar to those of duct-to-mucosa pancreaticojejunostomy. The suture threads placed in a square pattern surrounding the main pancreatic duct are observed.

\section{Supplementary Files}

This is a list of supplementary files associated with this preprint. Click to download.

- Table1.jpeg

- Table2.jpeg

- Table3.jpeg

- Table4.jpeg 
- Table5.jpeg

Page 35/35 